\title{
Propellantless AOCS Design for a 160-m, 450-kg Sailcraft of the Solar Polar Imager Mission
}

\author{
Bong Wie* \\ Arizona State University, Tempe, AZ 85287 \\ Stephanie Thomas ${ }^{\dagger}$ and Michael Paluszek ${ }^{\ddagger}$ \\ Princeton Satellite Systems, Princeton, NJ 08542 \\ and \\ David Murphy§ \\ ATK Space Systems, Goleta, CA 93117
}

\begin{abstract}
An attitude and orbit control system (AOCS) is developed for a 160-m, 450-kg solar sail spacecraft of the Solar Polar Imager (SPI) mission. The SPI mission is one of several SunEarth Connections solar sail roadmap missions currently envisioned by NASA. A reference SPI sailcraft consists of a $160-\mathrm{m}, 150-\mathrm{kg}$ square solar sail, a $250-\mathrm{kg}$ spacecraft bus, and $50-\mathrm{kg}$ science payloads, The $160-\mathrm{m}$ reference sailcraft has a nominal solar thrust force of $160 \mathrm{mN}$ (at $1 \mathrm{AU}$ ), an uncertain center-of-mass/center-of-pressure offset of $\pm 0.4 \mathrm{~m}$, and a characteristic acceleration of $0.35 \mathrm{~mm} / \mathrm{s}^{2}$. The solar sail is to be deployed after being placed into an earth escaping orbit by a conventional launch vehicle such as a Delta II. The SPI sailcraft first spirals inwards from $1 \mathrm{AU}$ to a heliocentric circular orbit at $0.48 \mathrm{AU}$, followed by a cranking orbit phase to achieve a science mission orbit at a $75-\mathrm{deg}$ inclination, over a total sailing time of 6.6 $\mathrm{yr}$. The solar sail will be jettisoned after achieving the science mission orbit. This paper focuses on the solar sailing phase of the SPI mission, with emphasis on the design of a reference AOCS consisting of a propellantless primary ACS and a microthruster-based secondary (optional) ACS. The primary ACS employs trim control masses running along mast lanyards for pitch/yaw control together with roll stabilizer bars at the mast tips for quadrant tilt (roll) control. The robustness and effectiveness of such a propellantless primary ACS would be enhanced by the secondary ACS which employs tip-mounted, lightweight pulsed plasma thrusters (PPTs). The microPPT-based ACS is mainly intended for attitude recovery maneuvers from off-nominal conditions. A relatively fast, 70-deg pitch reorientation within $3 \mathrm{hrs}$ every half orbit during the orbit cranking phase is shown to be feasible, with the primary ACS, for possible solar observations even during the 5-yr cranking orbit phase.
\end{abstract}

\section{Introduction}

Solar sails are envisioned as a propellantless, high-energy propulsion system for future space exploration missions. NASA's future missions enabled by solar sail propulsion include the Solar Polar Imager (SPI), L1-Diamond, Particle Acceleration Solar Orbiter (PASO), and Interstellar Probe, which are the Sun-Earth Connections (SEC) solar sail roadmap missions. ${ }^{1-3}$ In particular, the SPI mission is currently being further studied by NASA/JPL, and it is now called the SPI Vision mission. ${ }^{4}$ Our current understanding of the Sun is limited by a lack of observations of its polar regions. The SPI Vision mission utilizes a large solar sail to place a spacecraft in a 0.48-AU heliocentric circular orbit with an inclination of $75 \mathrm{deg}$. Viewing of the polar

*Professor, Dept. of Mechanical \& Aerospace Engineering, bong.wie@asu.edu, (480) 965-8674, Fax (480) 965-1384. Associate Fellow AIAA.

†Senior Technical Staff, 33 Witherspoon St., sjthomas@psatellite.com, (609) 279-9606, Fax (609) 279-9607. Member AIAA

‡President, 33 Witherspoon St., map@psatellite.com, (609) 279-9606, Fax (609) 279-9607. Member AIAA.

${ }^{\S}$ Chief Research Engineer, 600 Pine Ave, dave.murphy@atk.com, (805) 690-2439, Fax (805) 685-1369. Member AIAA. 


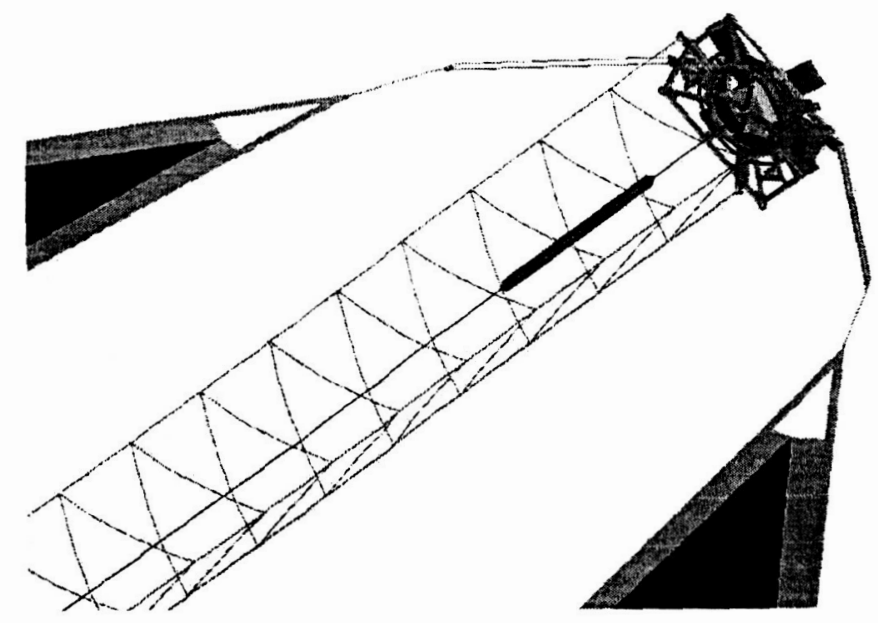

Figure 1. A solar sail mast with a trim ballast mass (running along a lanyard tape) and tip-mounted roll stabilizer bars attached to sail panels.

regions of the Sun provides a unique opportunity to more fully investigate the structure and dynamics of its interior, the generation of solar magnetic fields, the origin of the solar cycle, the causes of solar activity, and the structure and dynamics of the corona.

The SPI mission consists of the initial cruise phase (1.6 yr) to a 0.48-AU circular orbit, the cranking orbit phase ( $5 \mathrm{yr})$, and the science mission phase (2 yr). A $160-\mathrm{m}, 450-\mathrm{kg}$ solar sail spacecraft is considered for such a solar sailing mission. ${ }^{4}$ A Delta II launch vehicle is able to inject the 450 -kg SPI spacecraft into an earth escaping orbit with $C_{3}=0.25 \mathrm{~km}^{2} / \mathrm{s}^{2}$, and then the sail is to be deployed. The SPI sailcraft first spirals inwards from $1 \mathrm{AU}$ to a heliocentric circular orbit at $0.48 \mathrm{AU}$, then the cranking orbit phase begins to achieve a 75-deg inclination. The solar sail will be jettisoned after achieving the science mission orbit, and the total sailing time is approximately $6.6 \mathrm{yr}$.

This paper will focus on the attitude and orbit control of a large sailcraft during its solar sailing phase. A reference SPI sailcraft selected for AOCS design consists of a 160-m, 150-kg solar sail, a 250-kg spacecraft bus, and 50-kg science payloads. This $160-\mathrm{m}$ reference sailcraft has: a nominal solar thrust force of $160 \mathrm{mN}$ (at $1 \mathrm{AU}$ ), an uncertain center-of-mass/center-of-pressure offset of $\pm 0.4 \mathrm{~m}$, and a characteristic acceleration of $0.35 \mathrm{~mm} / \mathrm{s}^{2}$. A baseline AOCS architecture proposed for the SPI sailcraft consists of a propellantless primary ACS and a secondary ACS. The primary ACS employs trim control masses running along mast lanyards for pitch/yaw control together with roll stabilizer bars at the mast tips for quadrant tilt (roll) control. The secondary ACS employs tip-mounted, lightweight pulsed plasma thrusters (PPTs). MicroPPT modules are mounted at the tips of the sail booms providing a large control moment arm $(112 \mathrm{~m})$. The microPPT-based secondary ACS is mainly intended for attitude recovery maneuvers from off-nominal conditions. For more general sailing missions, where the sail is never jettisoned, this secondary ACS provides a lower-cost, lowermass propulsion for deployment control and greater redundancy than any traditional reaction-jet control system.

Either AOCS is able to perform a 70-deg pitch reorientation within $3 \mathrm{hrs}$ every half orbit during the orbit cranking phase. Such a relatively fast, orbit cranking maneuver is currently being considered by the SPI Vision mission study team for possible solar observations even during the 5-yr cranking orbit phase.

The remainder of this paper is outlined as follows. Section II describes the baseline AOCS architecture proposed for the 160-m SPI sailcraft. Section III describes an overview of the SPI Vision mission during its solar sailing phase. Section IV describes the attitude-trajectory coupled equations of motion of a sailcraft in a heliocentric orbit for attitude/orbit control design. Section V presents trajectory optimization results for the SPI Vision mission. Section VI presents the propellantless primary ACS design. 


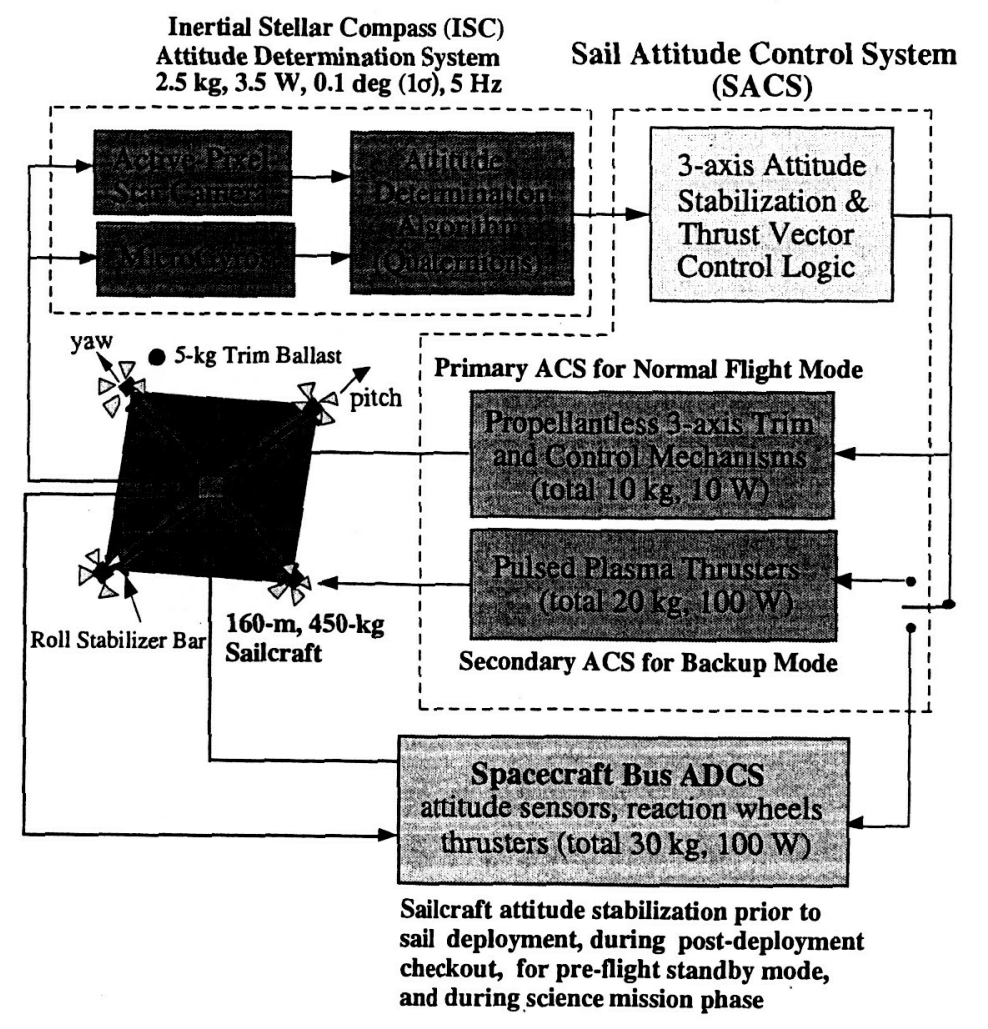

Figure 2. An integrated attitude and orbit control system (AOCS) architecture proposed for the 160-m, 450-kg SPI sailcraft.

\section{An Integrated AOCS Architecture of the SPI Sailcraft}

A baseline AOCS, consisting of a propellantless primary ACS and a microPPT-based secondary ACS, is proposed for a 160-m reference sailcraft of the SPI Vision mission. The primary ACS employs trim control masses (TCMs) running along mast lanyards for pitch/yaw control together with roll stabilizer bars (RSBs) at the mast tips for quadrant tilt control, as illustrated in Fig. 1. The robustness of such a propellantless primary ACS would be further enhanced by a secondary ACS utilizing tip-mounted, lightweight PPTs, which are also illustrated in Fig. 1. Such an optional microPPT-based ACS can be employed for attitude recovery maneuvers from off-nominal conditions as well as for a spin-stabilized safe mode. It can also be employed as a backup to the conventional ACS of the spacecraft prior to sail deployment and during pre-flight sail checkout operation, if necessary. A conventional bus ACS is required for the SPI mission as the sail is jettisoned at the start of the science mission phase. As an alternative to conventional approaches, the microPPT-based ACS option promises lower mass, lower cost, and greater redundancy.

The attitude determination system (ADS) is a critical subsystem of most spacecraft AOCS. An ADS of particular interest for solar sail applications is the Inertial Stellar Compass (ISC) recently developed by Draper Laboratory for an NMP ST6 flight validation experiment. ${ }^{6}$ The ISC is a miniature, low-power ADS developed for use with low-cost microsatellites. It is suitable for a wide range of future solar sail missions because of its low-mass, low-power, and low-volume design and its self-initializing, autonomous operational capability. The ISC is composed of a wide field-of-view active-pixel star camera and microgyros, with associated data processing and power electronics. It has a total mass of $2.5 \mathrm{~kg}$, a power requirement of $3.5 \mathrm{~W}$, and an accuracy of $0.1 \mathrm{deg}(1 \sigma)$. It is planned to be flight validated within few years. Some recent advances in microsatellite technologies, including the ISC, need to be exploited to complete an integrated low-cost, low-risk, low-mass, low-power, and low-volume AOCS for sailcraft.

The proposed AOCS architecture with various ADCS options, including a conventional ADCS for the spacecraft, is illustrated in Fig. 2. Detailed analysis and design of this baseline AOCS architecture, as 
applied to a fight validation mission of a 40-m solar sail in a dawn-dusk sunsynchronous orbit, can be found in Refs. 5,7-9. Other ACS options, employing a control boom or control vanes, can be be found in Ref. 10. A potential control-structure interaction caused by the significant torsion and bending of flexible masts of a large sailcraft is discussed in Ref. 11. The SPI mission architecture and its 160-m sailcraft equipped with the proposed baseline AOCS will be applicable with minimal modifications to a wide range of future solar sail flight missions with varying requirements and mission complexity, including a solar sailing mission for intercepting, impacting, and deflecting near-Earth asteroids. ${ }^{12,13}$ More details of the microPPT-based secondary ACS proposed for the SPI sailcraft can be found in Ref. 14.

\section{SPI Solar Sailing Mission Overview}

The SPI mission basically consists of the initial cruise phase (1.6 yr) to a 0.48 -AU circular orbit, the cranking orbit phase $(5 \mathrm{yr})$, and the science mission phase $(2 \mathrm{yr})$. The initial cruise phase of spiraling toward the sun using a simple in-plane steering law with a fixed 35-deg sun angle is illustrated in Fig. 3 for a reference sailcraft with a characteristic acceleration of $a_{c}=0.35 \mathrm{~mm} / \mathrm{s}^{2}$ (corresponding to a lightness number of $\lambda=0.06$ ). The characteristic launch energy, which is defined as the square of the hyperbolic excess speed $v_{\infty}$, was assumed as $C_{3}=0.25 \mathrm{~km}^{2} / \mathrm{s}^{2}$ for a Delta II launch vehicle. The initial position was simply assumed as $(X, Y)=(1,0)$ AU. In Fig. 3, the sailcraft speed is compared to the circular orbit speed (dotted red line) at the corresponding orbital position $r$ of the sailcraft. Although the use of this simple steering law does not exactly result in a circular orbit at $0.48 \mathrm{AU}$, it is presented here as a simple reference trajectory. Various optimization-based trajectories of the cruise phase will be discussed later in this paper.

The cranking orbit phase for achieving a 75-deg inclination by employing a simple out-of-plane steering law of \pm 35 -deg sun angle change every half orbit is illustrated in Fig. 4 . The elliptic orbital nature of the cranking orbit phase is due to the radial component of the solar radiation pressure force.

For typical solar sailing flight optimization problems, trajectory models which are decoupled from attitude dynamics were often used in the past. ${ }^{15-17}$ However, the effect of attitude motion of large solar sails on the solar sailing trajectory is of current practical concern. Consequently, the development of a six-degree-offreedom, orbit-attitude coupled dynamical model of solar sail spacecraft for trajectory optimization and simulation is of current practical importance. ${ }^{18,19}$

In the next section, a simple attitude-trajectory coupled dynamical model of solar sail spacecraft is described for attitude control design and integrated orbit-attitude control simulation. A quaternion-based attitude control system approach, previously developed in Refs. 20-22, is proposed for the AOCS design of the SPI sailcraft because of its simplicity of accommodating the thrust vector control command.

\section{Coupled Attitude and Orbital Dynamics}

The orientation of the solar sail thrust vector is often described in terms of the cone and clock angles. ${ }^{15-19}$ These two angles are the typical control inputs used in solar sailing trajectory optimization. However, there are at least two different sets of cone/clock angles selected for trajectory optimization in the literature. In this section, the trajectory-attitude coupled equations of motion, employing such two different sets of cone/clock angles, are briefly described for the purposes of trajectory design, attitude control design, and integrated orbit-attitude control simulation. Detailed discussions of such trajectory-attitude coupled equations of motion can be found in Ref. 19.

\section{A. Cone and Clock Angles}

Let $\{\hat{I}, \hat{J}, \hat{K}\}$ and $\{\hat{r}, \hat{\psi}, \hat{\phi}\}$ be respectively a set of right-handed, orthonormal vectors of the heliocentric ecliptic rectangular and spherical coordinate reference frames, as illustrated in Fig. 5 . The two angles, $\psi$ and $\phi$, are called the ecliptic longitude and latitude of the sailcraft position, respectively; $0 \leq \psi \leq 360$ deg and $-90 \mathrm{deg} \leq \phi \leq+90 \mathrm{deg}$.

The sailcraft position vector is then expressed as

$$
\begin{aligned}
\vec{r} & =r \hat{r} \\
& =(r \cos \phi \cos \psi) \hat{I}+(r \cos \phi \sin \psi) \hat{J}+(r \sin \phi) \hat{K} \\
& =X \hat{I}+Y \hat{J}+Z \hat{K}
\end{aligned}
$$



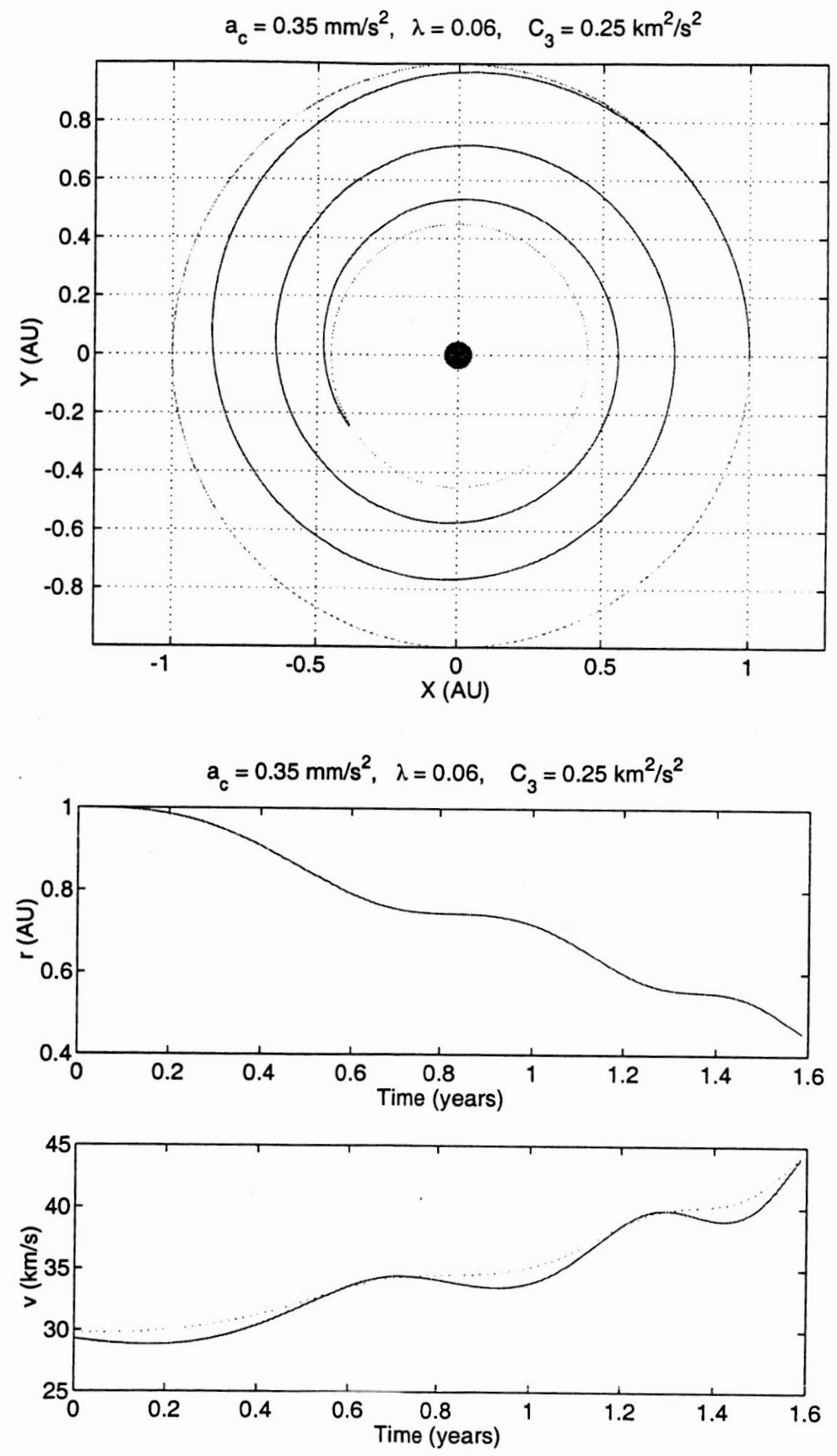

Figure 3. A simple reference trajectory of the initial cruise phase with a constant 35-deg sun angle. 

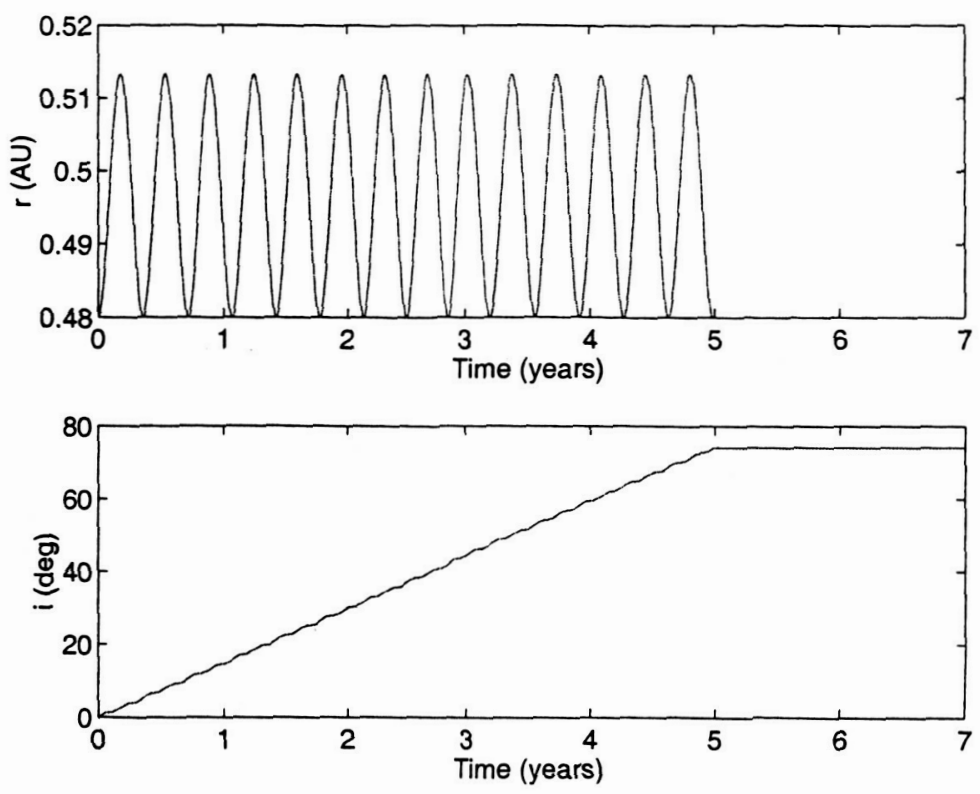

Figure 4. The cranking orbit phase for achieving a 75-deg inclination.

where $r=|\vec{r}|$ is the distance from the sun to the sailcraft.

The orientation of a unit vector normal to the sail plane, $\hat{n}$, is described in terms of the cone angle $\alpha$ and the clock angle $\beta$, illustrated in Fig. 6 , as follows:

$$
\hat{n}=(\cos \alpha) \hat{r}+(\sin \alpha \sin \beta) \hat{\psi}+(\sin \alpha \cos \beta) \hat{\phi}
$$

where

$$
\begin{gathered}
\cos \alpha=\hat{r} \cdot \hat{n} \\
\cos \beta=\frac{\hat{r} \times(\hat{n} \times \hat{r})}{|\hat{r} \times(\hat{n} \times \hat{r})|} \cdot \hat{\phi} \\
0 \leq \alpha \leq 90 \mathrm{deg} \\
0 \leq \beta \leq 360 \mathrm{deg}
\end{gathered}
$$

As also illustrated in Fig. 6, the sailcraft body-fixed basis vectors $\{\hat{1}, \hat{2}, \hat{3}\}$ are assumed to be aligned with $\{\hat{r}, \hat{\psi}, \hat{\phi}\}$ when $\alpha=\beta=0$, and the sailcraft roll axis is defined to be perpendicular to the sail surface; i.e., $\hat{1} \equiv \hat{n}$.

A different set of the cone and clock angles, $(\alpha, \delta)$, shown in Fig. 7, can also be employed as follows. Let $\{\hat{r}, \hat{\theta}, \hat{k}\}$ be a set of basis vectors of an osculating orbital plane, as illustrated in Fig. 8. A body-fixed rotational sequence to $\{\hat{1}, \hat{2}, \hat{3}\}$ from $\{\hat{I}, \hat{J}, \hat{K}\}$ is then described by successive coordinate transformations of the form ${ }^{21}$

$$
\mathbf{C}_{2}(-\alpha) \leftarrow \mathbf{C}_{1}(-\delta) \leftarrow \mathbf{C}_{3}(\theta) \leftarrow \mathbf{C}_{3}(\omega) \leftarrow \mathbf{C}_{1}(i) \leftarrow \mathbf{C}_{3}(\Omega)
$$

which becomes

$$
\begin{gathered}
{\left[\begin{array}{c}
\hat{r} \\
\hat{\theta} \\
\hat{k}
\end{array}\right]=\left[\begin{array}{ccc}
\cos (\omega+\theta) & \sin (\omega+\theta) & 0 \\
-\sin (\omega+\theta) & \cos (\omega+\theta) & 0 \\
0 & 0 & 1
\end{array}\right]\left[\begin{array}{ccc}
1 & 0 & 0 \\
0 & \cos i & \sin i \\
0 & -\sin i & \cos i
\end{array}\right]\left[\begin{array}{ccc}
\cos \Omega & \sin \Omega & 0 \\
-\sin \Omega & \cos \Omega & 0 \\
0 & 0 & 1
\end{array}\right]\left[\begin{array}{c}
\hat{I} \\
\hat{J} \\
\hat{K}
\end{array}\right]} \\
{\left[\begin{array}{c}
\hat{1} \\
\hat{2} \\
\hat{3}
\end{array}\right]=\left[\begin{array}{ccc}
\cos \alpha & 0 & \sin \alpha \\
0 & 1 & 0 \\
-\sin \alpha & 0 & \cos \alpha
\end{array}\right]\left[\begin{array}{ccc}
1 & 0 & 0 \\
0 & \cos \delta & -\sin \delta \\
0 & \sin \delta & \cos \delta
\end{array}\right]\left[\begin{array}{c}
\hat{r} \\
\hat{\theta} \\
\hat{k}
\end{array}\right]} \\
\text { American Institute of Aeronautics and Astronautics }
\end{gathered}
$$




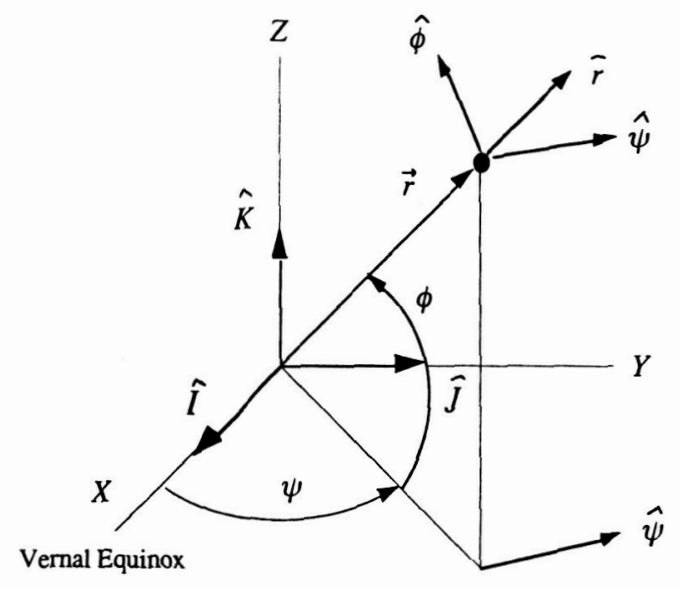

Figure 5. Heliocentric ecliptic rectangular coordinates $(X, Y, Z)$ and spherical coordinates $(r, \psi, \phi)$.

The orientation of a unit vector normal to the sail plane, $\hat{n}$, is then described in terms of $\alpha$ and $\delta$, as illustrated in Fig. 7, as follows:

$$
\hat{n}=(\cos \alpha) \hat{r}+(\sin \alpha \sin \delta) \hat{\theta}+(\sin \alpha \cos \delta) \hat{k}
$$

and

$$
\begin{gathered}
\cos \alpha=\hat{r} \cdot \hat{n} \\
\cos \delta=\frac{\hat{r} \times(\hat{n} \times \hat{r})}{|\hat{r} \times(\hat{n} \times \hat{r})|} \cdot \hat{k} \\
0 \leq \alpha \leq 90 \mathrm{deg} \\
0 \leq \delta \leq 360 \mathrm{deg}
\end{gathered}
$$

The two different clock angles, $\beta$ and $\delta$, are related as

$$
\begin{aligned}
& {\left[\begin{array}{ccc}
1 & 0 & 0 \\
0 & \cos \beta & -\sin \beta \\
0 & \sin \beta & \cos \beta
\end{array}\right]\left[\begin{array}{ccc}
\cos \phi & 0 & \sin \phi \\
0 & 1 & 0 \\
-\sin \phi & 0 & \cos \phi
\end{array}\right]\left[\begin{array}{ccc}
\cos \psi & \sin \psi & 0 \\
-\sin \psi & \cos \psi & 0 \\
0 & 0 & 1
\end{array}\right]} \\
& =\left[\begin{array}{ccc}
1 & 0 & 0 \\
0 & \cos \delta & -\sin \delta \\
0 & \sin \delta & \cos \delta
\end{array}\right]\left[\begin{array}{ccc}
\cos (\omega+\theta) & \sin (\omega+\theta) & 0 \\
-\sin (\omega+\theta) & \cos (\omega+\theta) & 0 \\
0 & 0 & 1
\end{array}\right]\left[\begin{array}{ccc}
1 & 0 & 0 \\
0 & \cos i & \sin i \\
0 & -\sin i & \cos i
\end{array}\right]\left[\begin{array}{ccc}
\cos \Omega & \sin \Omega & 0 \\
-\sin \Omega & \cos \Omega & 0 \\
0 & 0 & 1
\end{array}\right]
\end{aligned}
$$

\section{B. Solar Radiation Pressure Force}

An ideal model of the solar radiation pressure (SRP) force is considered here. The SRP force vector (per unit mass) acting on the sailcraft is then described in various coordinates as follows:

$$
\begin{aligned}
\vec{F} & =F_{0}(\hat{r} \cdot \hat{n})^{2} \hat{n} \\
& =F_{r} \hat{r}+F_{\psi} \hat{\psi}+F_{\phi} \hat{\phi} \\
& =R \hat{r}+T \hat{\theta}+N \hat{k} \\
& =F_{X} \hat{I}+F_{Y} \hat{J}+F_{Z} \hat{K}
\end{aligned}
$$

where

$$
\begin{gathered}
F_{0}=\left(\frac{r_{\oplus}}{r}\right)^{2} a_{c} \\
7 \text { of } 25
\end{gathered}
$$



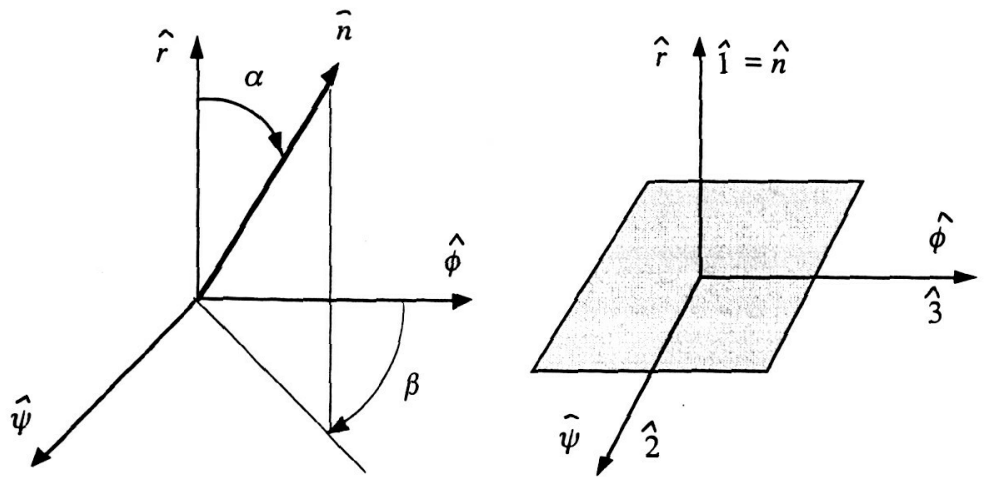

Figure 6. Cone angle $\alpha$, clock angle $\beta$, and sailcraft orientation when $\alpha=\beta=0$.

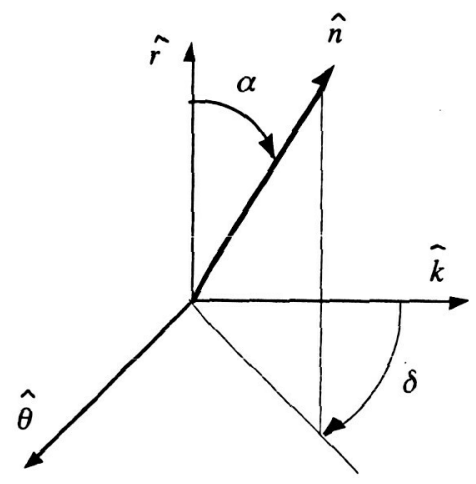

Figure 7. Cone angle $\alpha$ and clock angle $\delta$ (Ref. 15).

where $r_{\oplus}=1 \mathrm{AU}=149597870.691 \mathrm{~km}$ is the mean distance from the sun to the earth, and $a_{c}$ is the characteristic acceleration of the sailcraft at $1 \mathrm{AU}$ defined as

$$
a_{c}=\frac{F_{s}}{m}=\frac{2 \eta P A}{m}=\eta\left(9.1 \times 10^{-6}\right) A / m
$$

and $F_{s}$ is the nominal solar thrust force at $1 \mathrm{AU}$ for an ideal flat solar sail with a reflectivity coefficient $\eta$ and a sail area of $A$.

Furthermore, we have

$$
\begin{aligned}
& {\left[\begin{array}{l}
F_{r} \\
F_{\psi} \\
F_{\phi}
\end{array}\right]=F_{0} \cos ^{2} \alpha\left[\begin{array}{c}
\cos \alpha \\
\sin \alpha \sin \beta \\
\sin \alpha \cos \beta
\end{array}\right]} \\
& {\left[\begin{array}{c}
R \\
T \\
N
\end{array}\right]=F_{0} \cos ^{2} \alpha\left[\begin{array}{c}
\cos \alpha \\
\sin \alpha \sin \delta \\
\sin \alpha \cos \delta
\end{array}\right]}
\end{aligned}
$$

$$
8 \text { of } 25
$$




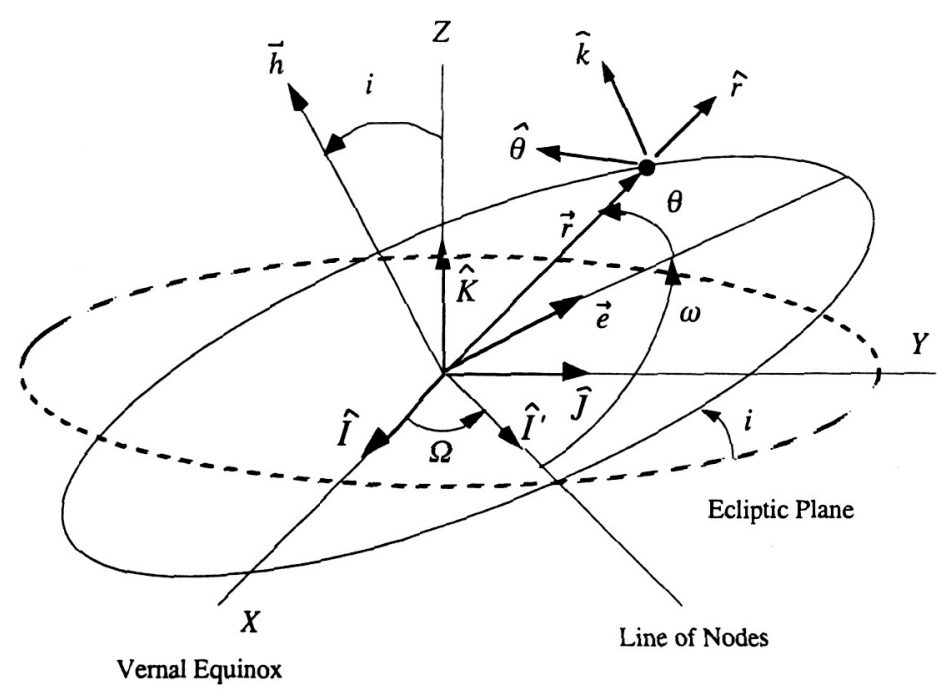

Figure 8. Orbital geometry (illustrated for a near-circular orbit).

\section{Gauss's Form of the Variational Equations (Osculating Orbital Elements)}

Various forms of trajectory equations are available, as described in Ref. 19. For the purpose of preliminary trajectory design, attitude control design, and integrated orbit-attitude control simulation, Gauss's form of the variational equations in terms of osculating orbital elements is chosen here although this set of equations have a singularity problem when $i=0$.

A set of six first-order differential equations, called Gauss's form of the variational equations, in terms of osculating orbital elements, are given by ${ }^{23}$

$$
\begin{aligned}
\dot{a} & =\frac{2 a^{2}}{h}[e R \sin \theta+T(1+e \cos \theta)] \equiv \frac{2 a^{2}}{h}\left[e R \sin \theta+\frac{p T}{r}\right] \\
\dot{e} & =\sqrt{\frac{p}{\mu}}[R \sin \theta+T(\cos \theta+\cos E)] \equiv \frac{1}{h}\{p R \sin \theta+[(p+r) \cos \theta+r e] T\} \\
\dot{i} & =\frac{r \cos (\omega+\theta)}{h} N \\
\dot{\Omega} & =\frac{r \sin (\omega+\theta)}{h \sin i} N \\
\dot{\omega} & =-\frac{r \sin (\omega+\theta)}{h \tan i} N+\frac{1}{e h}[-p R \cos \theta+(p+r) T \sin \theta] \\
\dot{\theta} & =\frac{h}{r^{2}}+\frac{1}{e h}[p R \cos \theta-(p+r) T \sin \theta]
\end{aligned}
$$

where

$$
\begin{gathered}
p=a\left(1-e^{2}\right) \\
r=\frac{p}{1+e \cos \theta} \equiv a(1-e \cos E) \\
h=\sqrt{\mu p}=n a^{2} \sqrt{1-e^{2}} \\
n=\sqrt{\mu / a^{3}}
\end{gathered}
$$

\section{Attitude Dynamics and Control Model Employing Quaternions}

A quaternion-feedback attitude control system approach, previously developed in Refs. 20-22, is proposed for solar sail attitude applications because of its simplicity of accommodating the commanded cone and clock angles of the solar thrust vector into a solar sail attitude control system.

$$
9 \text { of } 25
$$

American Institute of Aeronautics and Astronautics 
Euler's attitude dynamical equations of motion of a rigid sailcraft are given by

$$
\begin{aligned}
& I_{1} \dot{\omega}_{1}-\left(I_{2}-I_{3}\right) \omega_{2} \omega_{3}=u_{1}+d_{1} \\
& I_{2} \dot{\omega}_{2}-\left(I_{3}-I_{1}\right) \omega_{3} \omega_{1}=u_{2}+d_{2} \\
& I_{3} \dot{\omega}_{3}-\left(I_{1}-I_{2}\right) \omega_{1} \omega_{2}=u_{3}+d_{3}
\end{aligned}
$$

where $\left(\omega_{1}, \omega_{2}, \omega_{3}\right)$ are the angular velocity components, $\left(I_{1}, I_{2}, I_{3}\right)$ the principal moments of inertia, $\left(u_{1}, u_{2}, u_{3}\right)$ the attitude control torques, and $\left(d_{1}, d_{2}, d_{3}\right)$ the disturbance torques.

The kinematic differential equations in terms of attitude quaternions are described as

$$
\left[\begin{array}{c}
\dot{q}_{1} \\
\dot{q}_{2} \\
\dot{q}_{3} \\
\dot{q}_{4}
\end{array}\right]=\frac{1}{2}\left[\begin{array}{cccc}
0 & \omega_{3} & -\omega_{2} & \omega_{1} \\
-\omega_{3} & 0 & \omega_{1} & \omega_{2} \\
\omega_{2} & -\omega_{1} & 0 & \omega_{3} \\
-\omega_{1} & -\omega_{2} & -\omega_{3} & 0
\end{array}\right]\left[\begin{array}{l}
q_{1} \\
q_{2} \\
q_{3} \\
q_{4}
\end{array}\right]
$$

where $\left(q_{1}, q_{2}, q_{3}, q_{4}\right)$ are the inertial attitude quaternions which are the typical outputs from an attitude determination system as illustrated in Fig. 2 .

The quaternion-feedback attitude control logic, proposed for solar sailing applications, is simply a PID control logic of the form ${ }^{19-21}$

$$
\begin{aligned}
& u_{1}=-K_{1}\left(e_{1}+\frac{1}{\tau_{i}} \int e_{1} d t\right)-D_{1} \omega_{1} \\
& u_{2}=-K_{2}\left(e_{2}+\frac{1}{\tau_{i}} \int e_{2} d t\right)-D_{2} \omega_{2} \\
& u_{3}=-K_{3}\left(e_{3}+\frac{1}{\tau_{i}} \int e_{3} d t\right)-D_{3} \omega_{3}
\end{aligned}
$$

where $\left(e_{1}, e_{2}, e_{3}\right)$ are the roll, pitch, and yaw components of attitude-error quaternions $\left(e_{1}, e_{2}, e_{3}, e_{4}\right)$, and $\left(K_{i}, \tau_{i}, D_{i}\right)$ are PID control gains to be properly determined. by

A saturation control logic of accommodating the actuator torque and slew rate constraints is also given

$$
u_{i}=-\underset{U_{\max }}{\operatorname{sat}}\left\{K_{i} \operatorname{sat}_{L_{i}}\left[e_{i}+\frac{1}{\tau_{i}} \int e_{i} d t\right]+D_{i} \omega_{i}\right\} ; \quad i=1,2,3
$$

and the variable limiter $L_{i}$ is self-adjusted as

$$
L_{i}=\frac{D_{i}}{K_{i}} \min \left\{\sqrt{2 a_{i}\left|e_{i}\right|}, \omega_{\max }\right\}
$$

where $\omega_{\max }$ is the maximum slew rate constraint for each axis (if required) and $a_{i}$ is the maximum angular control acceleration. Details of this nonlinear PID control logic which is applicable to solar sail attitude control can be found in Refs. 21-22.

The attitude-error quaternions are computed using the desired or commanded attitude quaternions $\left(q_{1 c}, q_{2 c}, q_{3 c}, q_{4 c}\right)$ and the actual inertial attitude quaternions $\left(q_{1}, q_{2}, q_{3}, q_{4}\right)$, as follows:

$$
\left[\begin{array}{l}
e_{1} \\
e_{2} \\
e_{3} \\
e_{4}
\end{array}\right]=\left[\begin{array}{cccc}
q_{4 c} & q_{3 c} & -q_{2 c} & -q_{1 c} \\
-q_{3 c} & q_{4 c} & q_{1 c} & -q_{2 c} \\
q_{2 c} & -q_{1 c} & q_{4 c} & -q_{3 c} \\
q_{1 c} & q_{2 c} & q_{3 c} & q_{4 c}
\end{array}\right]\left[\begin{array}{l}
q_{1} \\
q_{2} \\
q_{3} \\
q_{4}
\end{array}\right]
$$

The desired attitude quaternions $\left(q_{1 c}, q_{2 c}, q_{3 c}, q_{4 c}\right)$, corresponding to the desired solar thrust vector direction described by $(\alpha, \beta)$, are given by

$$
\left[\begin{array}{l}
q_{1 c} \\
q_{2 c} \\
q_{3 c} \\
q_{4 c}
\end{array}\right]=\left[\begin{array}{cccc}
\cos (\alpha / 2) & 0 & \sin (\alpha / 2) & 0 \\
0 & \cos (\alpha / 2) & 0 & -\sin (\alpha / 2) \\
-\sin (\alpha / 2) & 0 & \cos (\alpha / 2) & 0 \\
0 & \sin (\alpha / 2) & 0 & \cos (\alpha / 2)
\end{array}\right]\left[\begin{array}{cccc}
\cos (\beta / 2) & 0 & 0 & -\sin (\beta / 2) \\
0 & \cos (\beta / 2) & -\sin (\beta / 2) & 0 \\
0 & \sin (\beta / 2) & \cos (\beta / 2) & 0 \\
\sin (\beta / 2) & 0 & 0 & \cos (\beta / 2)
\end{array}\right]
$$




$$
\times\left[\begin{array}{cccc}
\cos (\phi / 2) & 0 & \sin (\phi / 2) & 0 \\
0 & \cos (\phi / 2) & 0 & -\sin (\phi / 2) \\
-\sin (\phi / 2) & 0 & \cos (\phi / 2) & 0 \\
0 & \sin (\phi / 2) & 0 & \cos (\phi / 2)
\end{array}\right]\left[\begin{array}{c}
0 \\
0 \\
\sin (\psi / 2) \\
\cos (\psi / 2)
\end{array}\right]
$$

where $\psi$ and $\phi$ are the ecliptic longitude and latitude of a sailcraft inertial position, respectively, as shown in Fig. 5.

The desired attitude quaternions $\left(q_{1 c}, q_{2 c}, q_{3 c}, q_{4 c}\right)$, corresponding to the desired solar thrust vector direction described by $(\alpha, \delta)$, are given by

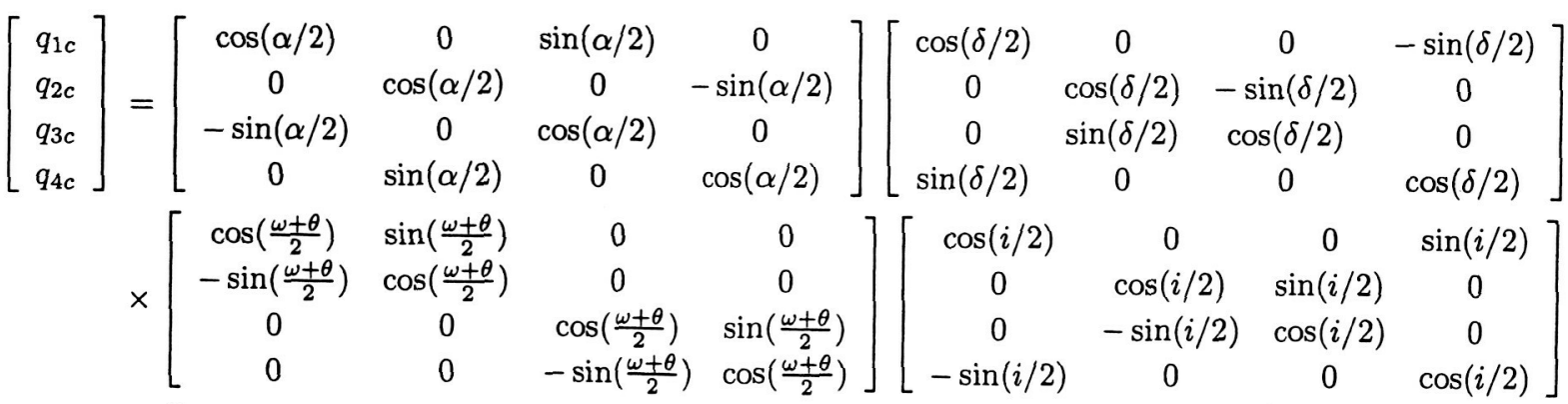

$$
\begin{aligned}
& \times\left[\begin{array}{c}
0 \\
0 \\
\sin (\Omega / 2) \\
\cos (\Omega / 2)
\end{array}\right]
\end{aligned}
$$

where $i, \omega, \Omega$, and $\theta$ are the various orbital angles shown in Fig, 8.

\section{Solar Sailing Trajectory Optimization for the SPI Mission}

Some preliminary study results of developing solar sail trajectory optimization tools, as applied to the SPI mission, are presented here. Optimization approaches under study are indirect-method global optimizers such as downhill simplex, genetic algorithms, and simulated annealing.

Figure 9 shows a baseline, optimal trajectory design by Carl Sauer at JPL for achieving a circular orbit at $0.48 \mathrm{AU}$ with a $75-\mathrm{deg}$ inclination. The monotonically decreasing semimajor axis and the corresponding variation of eccentricity can be seen in this figure during the initial cruise phase to $0.48 \mathrm{AU}$. The eccentricity remains constant during the orbit cranking phase. The eccentricity is finally nulled after cranking is complete. The sail angles $\left(\alpha^{*}, \delta^{*}\right)$ in Fig. 9 are the optimal cone and clock angles, respectively. However, the clock angle shown in Fig. 9 is actually $\beta$ defined in Fig. 6, not $\delta$ as defined in Fig. 7. Note that the cone angle, $\alpha$, is nearly kept constant at 35 deg throughout the sailing mission.

Simple sail-steering laws for maximizing the rate of change of the semimajor axis and the inclination, described in Ref. 15, were applied to the SPI mission. These sail-steering laws are based on the variational orbit equations to optimally change individual orbit elements, and they provide the optimal cone and clock angles $\left(\alpha^{*}, \delta^{*}\right)$ in closed, analytical form. Figure 10 shows the result of applying these simple sail-steering laws, given by Eqs. (4.56), (4.63), and (4.70) of Ref. 15, to the SPI mission. The switch from orbit radius reduction to the cranking phase occurs once the sail reaches the target semimajor axis of $0.48 \mathrm{AU}$. The simulation used a nominal characteristic acceleration of $0.312 \mathrm{~mm} / \mathrm{s}^{2}$ (at $1 \mathrm{AU}$ ), an 8-deg initial inclination, and $C_{3}=0.25 \mathrm{~km}^{2} / \mathrm{s}^{2}$. The sailcraft achieves the desired semimajor axis and inclination but the final orbit is eccentric while the desired SPI mission orbit is circular. The corresponding three-dimensional orbital trajectory is illustrated in Fig. 11. Note that the semimajor-axis control law described in Ref. 15 was not intended to be used for controlling both the semimajor axis and the eccentricity. Such a simple sailsteering law in closed, analytical form was examined as the first step towards developing solar sail trajectory optimization tools.

In an attempt to control the semimajor axis and the eccentricity simultaneously, we have applied the indirect methods to the initial cruise phase for achieving a circular orbit at $0.48 \mathrm{AU}$. Figure 12 shows the result of applying the semimajor axis change optimization using Downhill-Simplex, a global optimization method 


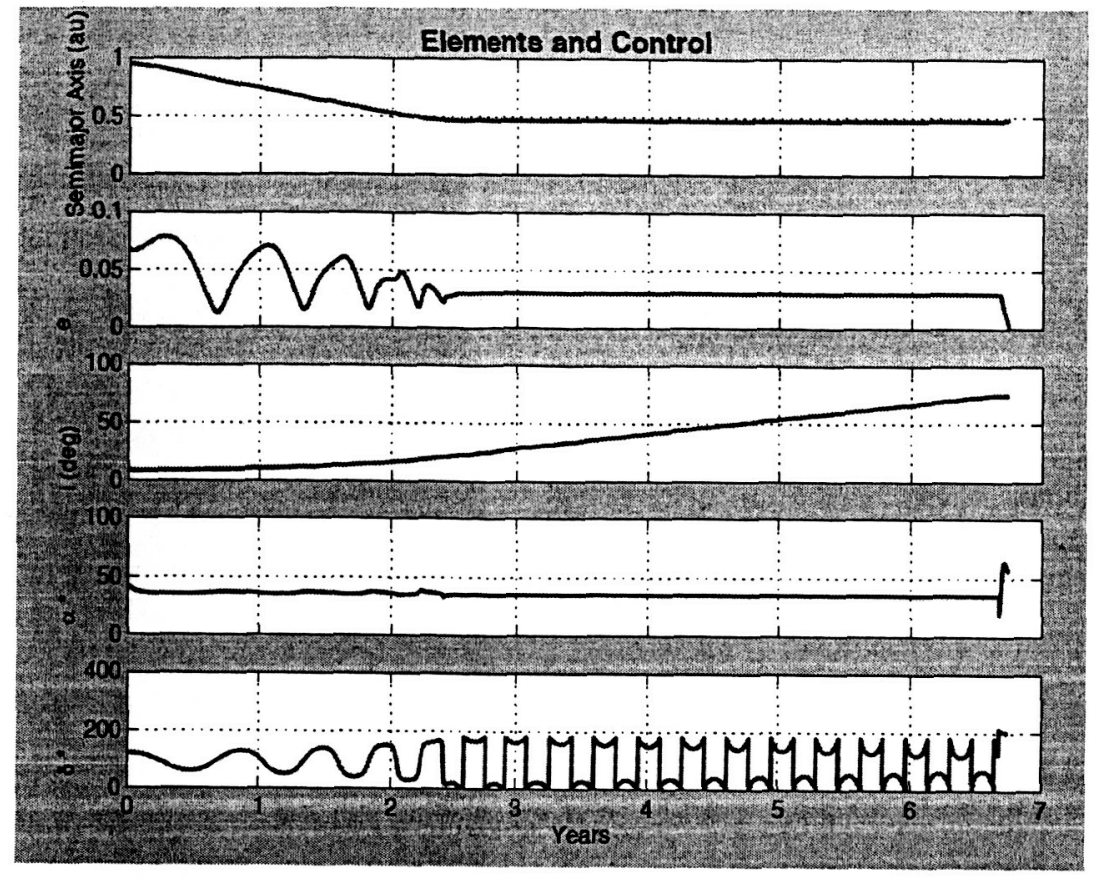

Figure 9. A baseline, optimal trajectory design by Carl Sauer at JPL $\left(C_{3}=0.25 \mathrm{~km}^{2} / \mathrm{s}^{2}\right)$.

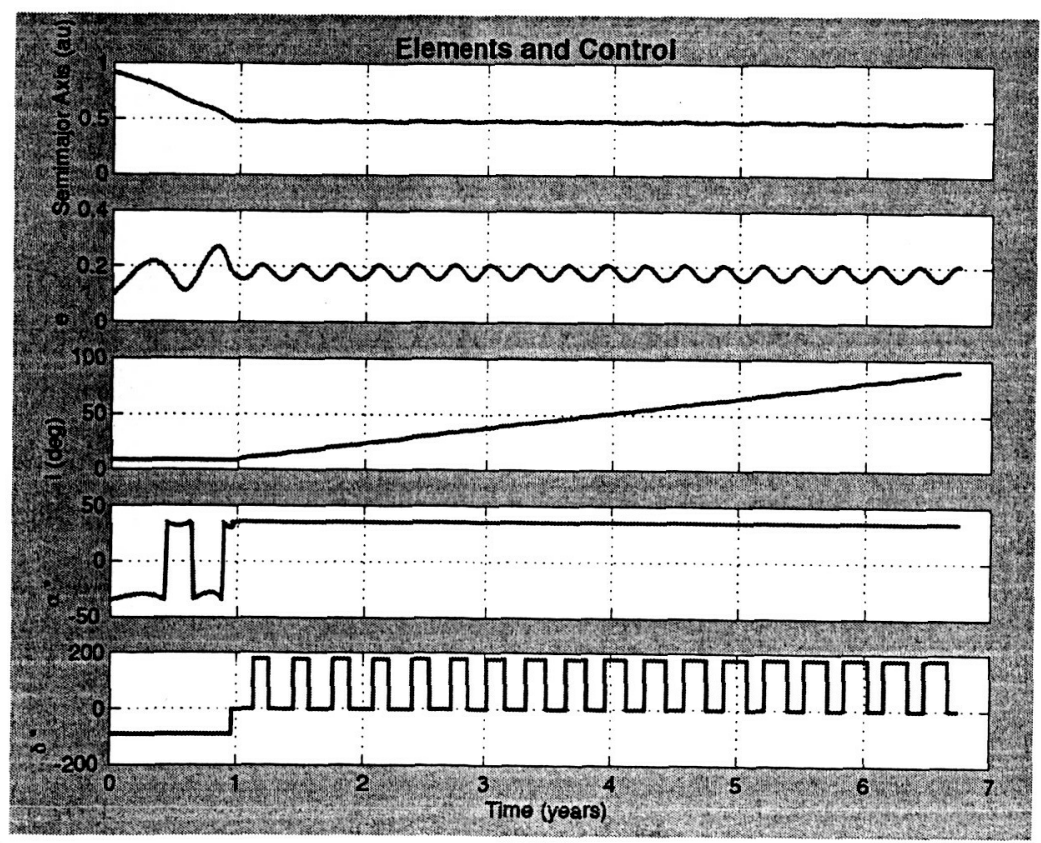

Figure 10. The result of employing simple sail-steering laws for optimally changing the semimajor axis and the inclination $\left(C_{3}=0.25 \mathrm{~km}^{2} / \mathrm{s}^{2}\right)$. The eccentricity is not directly controlled. 


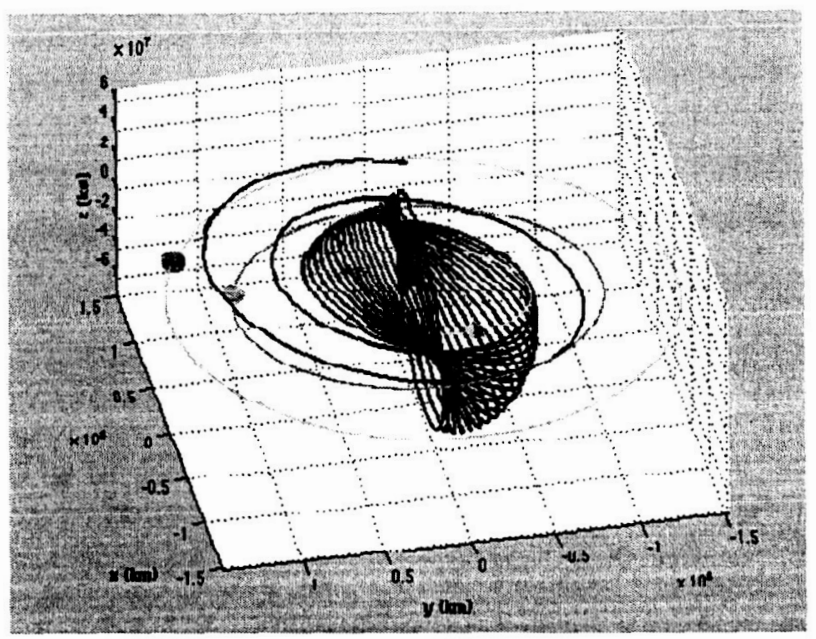

Figure 11. Three-dimensional trajectory illustration for employing simple sail-steering laws for optimally changing the semimajor axis and the inclination.

available in MATLAB. Downhill-Simplex searches for the initial costates given the boundary conditions. The trajectory reaches $0.48 \mathrm{AU}$ with leftover eccentricity, although at some points the eccentricity is very small. The period of the eccentricity oscillation is clearly shrinking and the eccentricity is not growing but is instead also dropping in magnitude. In both of these ways the result is qualitatively similar to the baseline optimal trajectory design by Carl Sauer, indicating that the optimization is capable of controlling semimajor axis and eccentricity together but is just not driving the eccentricity down enough. The results are a complex combination of the weightings on the final state errors and the final conditions on the numerical integration, which currently exits once the target radius is reached. Further work is necessary to determine a methodology for selecting the weights and terminating the initial conditions.

A solar sailing kinetic energy interceptor (KEI) mission, which requires at least ten $160-\mathrm{m}, 300-\mathrm{kg}$ solar sail spacecraft with a characteristic acceleration of $0.5 \mathrm{~mm} / \mathrm{s}^{2}$, is proposed in Ref. 12 as a viable nearterm option for mitigating the threat posed by near-Earth asteroids (NEAs). The solar sailing phase of the proposed KEI mission, which is very similar to that of the SPI mission, is comprised of the initial cruise phase from $1 \mathrm{AU}$ to $0.25 \mathrm{AU}$, the cranking orbit phase (for a 168-deg inclination change), and the final retrograde orbit phase prior to intercepting the target asteroid at its perihelion. A solar sailing KEI trajectory design for optimal intercept/impact/deflection of NEAs, which is applicable to the SPI trajectory design, can be found in Ref. 13.

\section{Attitude Control of the SPI Sailcraft Using TCMs and RSBs}

\section{A. A Simplified Dynamical Model}

Consider a 160-m SPI sailcraft in a heliocentric orbit equipped with trim control masses (TCMs) and roll stabilizer bars (RSBs). The roll axis is perpendicular to the sail plane and it often nominally points toward the sun (but not necessarily). The pitch and yaw axes are the transverse axes along the masts. A dynamical model consists of a rigid sailcraft of mass $M$ and two trim ballasts of each mass of $m$, as shown in Fig. 13 . The origin of the body-fixed reference frame is located at point $O$, which is assumed to be the center of mass of a sailcraft of mass $M$ excluding the ballast masses. It is also assumed that TCMs are running along mast lanyards (i.e., along the pitch and yaw axes).

A set of simplified attitude equations of motion are considered for control design, as follows: ${ }^{7}$

$$
\begin{aligned}
& J_{1} \dot{\omega}_{1}=u_{1}+d_{1} \\
& J_{2} \dot{\omega}_{2}=u_{2}+d_{2} \\
& J_{3} \dot{\omega}_{3}=u_{3}+d_{3}
\end{aligned}
$$



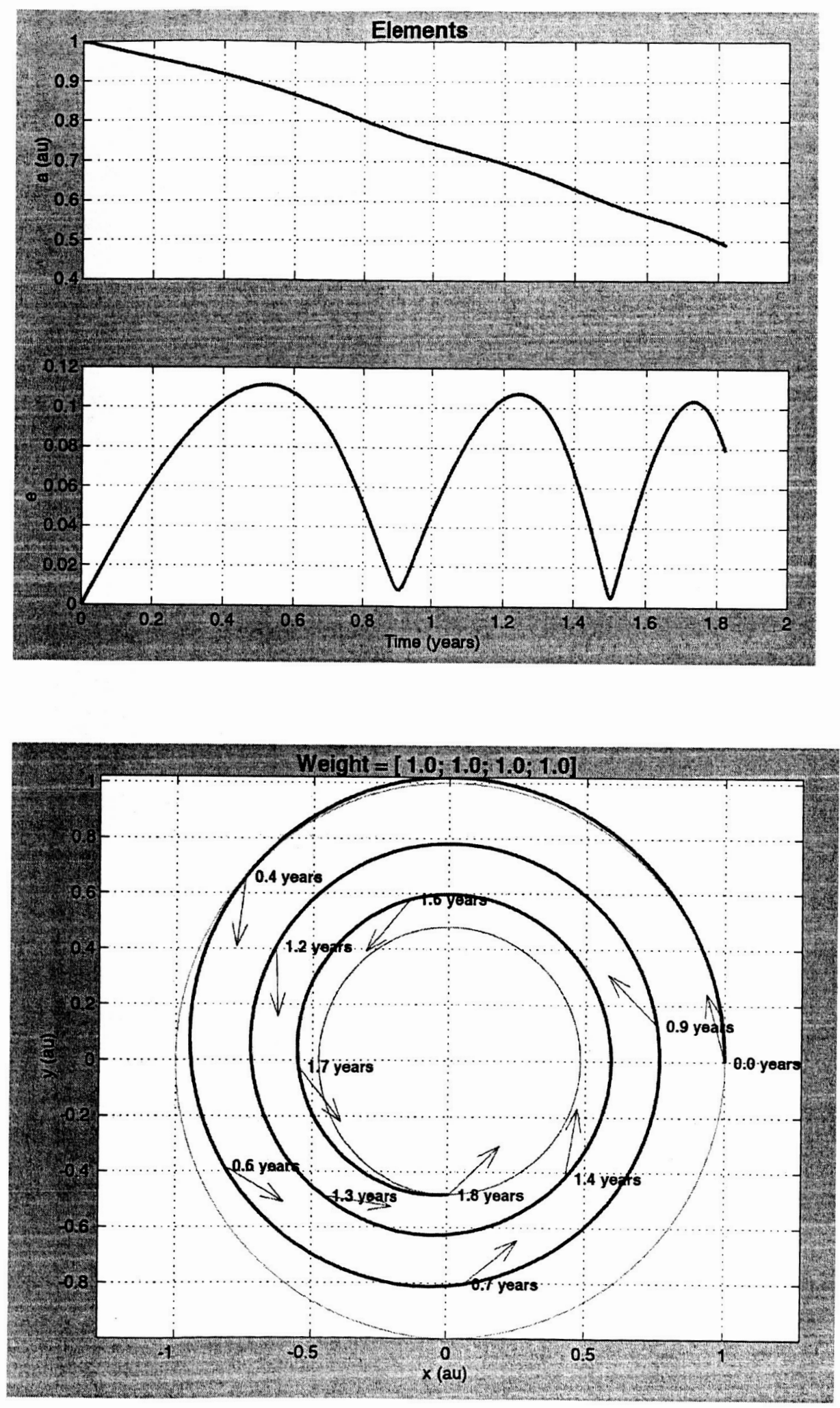

Figure 12. The result of employing the semimajor axis change optimization using Downhill-Simplex. 


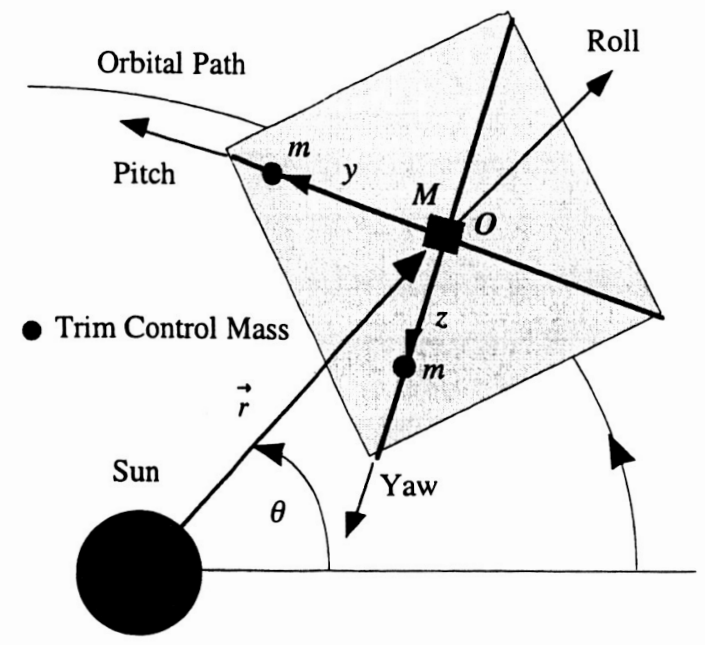

Figure 13. A solar sail spacecraft with trim control masses in a sun-centered orbit.

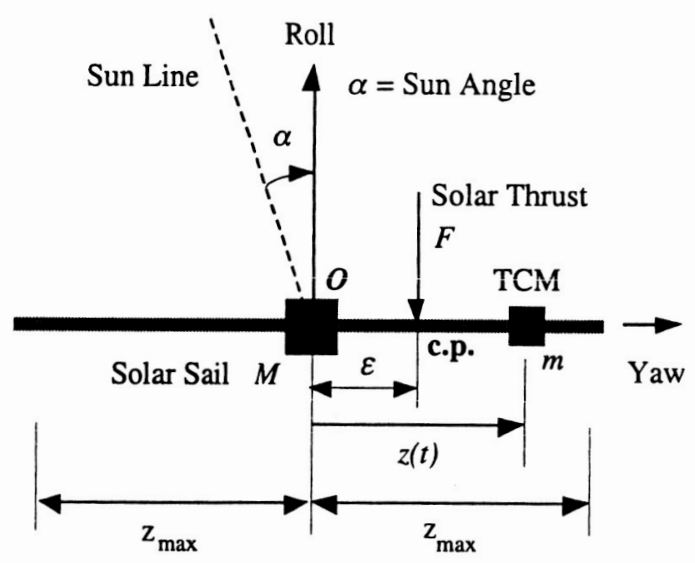

Figure 14. A dynamic model of sailcraft with a trim control mass moving along the yaw axis to generate a pitch control torque.

$$
\begin{gathered}
u_{1}=C \sin \delta \\
u_{2}=-\frac{m_{r} F}{M} z \\
u_{3}=\frac{m_{r} F}{M} y \\
d_{1}= \pm 0.5 \epsilon F, \quad d_{2}=d_{3}= \pm \epsilon F \\
J_{1}=I_{1}+m_{r}\left(y^{2}+z^{2}\right) \\
J_{2}=I_{2}+m_{r} z^{2} \\
J_{3}=I_{3}+m_{r} y^{2}
\end{gathered}
$$

where $\delta$ is the RSB tilt angle, $C$ is the RSB control scale factor, $y$ and $z$ are the TCM positions along the pitch and yaw axes, respectively, $F$ is the solar radiation pressure force defined as

$$
F \approx\left(\frac{r_{\oplus}}{r}\right)^{2} F_{s} \cos ^{2} \alpha=2 \eta P A\left(\frac{r_{\oplus}}{r}\right)^{2} \cos ^{2} \alpha
$$

$$
15 \text { of } 25
$$


and $m_{r}$ is the so-called reduced mass defined as

$$
m_{r}=\frac{m(M+m)}{M+2 m}
$$

Note that $m_{r} \approx m$ because $M \gg m$.

A reference 160-m SPI sailcraft model for AOCS design is assumed as

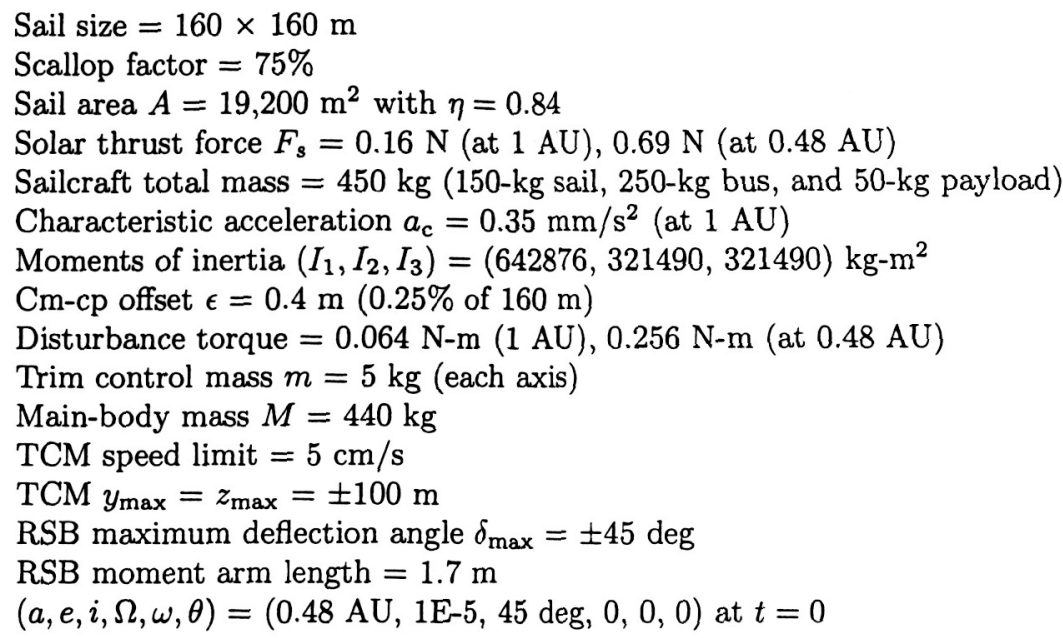

\section{B. Roll-Axis Control Design}

The roll-axis control logic is assumed as

$$
u_{1}=-\operatorname{sat}_{U_{\max }}\left\{K_{1} \operatorname{sat}_{L_{1}}\left[e_{1}+\frac{1}{\tau_{i}} \int e_{1} d t\right]+D_{1} \omega_{1}\right\}
$$

where $u_{1}$ is the roll control torque command with a saturation limit of $U_{\max }=C \sin \delta_{\max }$ and the variable limiter $L_{1}$ is self-adjusted as

$$
L_{1}=\frac{C_{1}}{D_{1}} \min \left\{\sqrt{2 a_{1}\left|e_{1}\right|}, \omega_{\max }\right\}
$$

where $a_{1}=U_{\max } / J_{1}$ and $\omega_{\max }$ is assumed to be constrained as $0.1 \mathrm{deg} / \mathrm{s}$.

The roll control torque $u_{1}$ (in units of $\mathrm{N}-\mathrm{m}$ ) is related to the tilt angle $\delta$ of the RSB of an assumed moment arm length of $1.7 \mathrm{~m}$ for a $160-\mathrm{m}$ sailcraft, as follows:

$$
u_{1}=C \sin \delta \approx \frac{(1.7)(53.2)}{80} F \sin \delta
$$

It is assumed that all 4 RSBs are rotated simultaneously. Consequently, we have $U_{\max }$ of $\pm 0.15 \mathrm{~N}-\mathrm{m}$ (at 1 $\mathrm{AU})$ for a maximum tilt angle of $\pm 45 \mathrm{deg}$.

The RSB actuator dynamics is also assumed as

$$
T \dot{\delta}+\delta=\delta_{c} ; \quad\left|\delta_{c}(t)\right| \leq \delta_{\max }
$$

where $T$ is the actuator time constant, $\delta$ is the actual tilt angle, and $\delta_{c}$ is the commanded tilt angle (the control input) with a maximum value of $\delta_{\max }$. The commanded tilt angle of the RSB is then given by

$$
\delta_{c}=\arcsin \left\{\frac{80 u_{1}}{(1.7)(53.2) F}\right\} \approx \frac{80 u_{1}}{(1.7)(53.2) F}
$$

where

$$
F \approx 0.16\left(\frac{r_{\oplus}}{r}\right)^{2} \cos ^{2} \alpha
$$

and $u_{1}$ is given by Eq. 25 . 


\section{Pitch/Yaw Control Design}

The steady-state trim position of the pitch TCM for countering the effect of the $\mathrm{cm} / \mathrm{cp}$ offset $\epsilon$ can be estimated as

$$
z_{s s}=\frac{M}{m_{r}} \epsilon \approx \frac{M}{m} \epsilon= \pm 35 \mathrm{~m}
$$

The actuator dynamics of the pitch TCM is assumed as

$$
T \dot{z}+z=z_{c} ; \quad\left|z_{c}(t)\right| \leq z_{\max }
$$

where $T$ is the actuator time constant, $z$ is the actual position, and $z_{c}$ is the commanded position (the control input) with a maximum value of $z_{\max }$. For a reference control design, it is assumed that $z_{\max }= \pm 100 \mathrm{~m}$, $\dot{z}_{\max }= \pm 0.05 \mathrm{~m} / \mathrm{s}$, and $T=200 \mathrm{sec}$ for a $160-\mathrm{m}$ sailcraft with $M=440 \mathrm{~kg}, m=5 \mathrm{~kg}$, and $\epsilon= \pm 0.4 \mathrm{~m}$.

The pitch control logic is assumed as

$$
z_{c}=\operatorname{sat}_{z_{\max }}\left\{K_{2} \operatorname{sat}_{L_{2}}\left[e_{2}+\frac{1}{\tau_{2}} \int e_{2} d t\right]+D_{2} \omega_{2}\right\}
$$

where $\tau$ is the time constant of integral control and variable limiter $L_{2}$ is self-adjusted as

$$
L_{2}=\frac{D_{2}}{K_{2}} \min \left\{\sqrt{2 a_{2}\left|e_{2}\right|}, \omega_{\max }\right\}
$$

Similarly, we have the yaw control logic as

$$
y_{c}=-\operatorname{sat}_{y_{\max }}\left\{K_{3} \operatorname{sat}_{L_{3}}\left[e_{3}+\frac{1}{\tau_{3}} \int e_{3} d t\right]+D_{3} \omega_{3}\right\}
$$

where $y_{\max }= \pm 100 \mathrm{~m}$.

\section{Simulation Example: Cranking Orbit Phase at 0.48 AU}

An attitude maneuver for achieving a desired 180-deg $\delta$ clock-angle change within $3 \mathrm{hrs}$ (with a fixed coneangle command of $35 \mathrm{deg}$ ) is illustrated in Figs. 15-17. An equivalent, direct 70-deg pitch maneuver within $3 \mathrm{hrs}$ is also demonstrated in Figs. 18-20. Deviations from the desired cone and clock angles, as can be seen in these figures, are caused by the nature of the propellantless attitude control in the presence of solar disturbance torques. An inclination increase of $0.06 \mathrm{deg} /$ day can be seen in Fig. 21 for the cranking orbit phase of the SPI mission. These preliminary AOCS design results are being validated in using a high-fidelity dynamical model of the $160-\mathrm{m}$ sailcraft with actuator nonlinearities and structural flexibility. ${ }^{11}$ The robustness of a propellantless primary ACS described in the preceding section can be further enhanced by a secondary ACS utilizing tip-mounted, lightweight pulsed plasma thrusters (PPTs). The microPPTbased ACS is mainly intended for attitude recovery maneuvers from off-nominal conditions. Details of the microPPT-based ACS design for solar sail spacecraft can be found in Refs. 8 and 14.

\section{Conclusion}

In this paper, a baseline attitude and orbit control system (AOCS) has been developed for a 160-m, 450-kg solar sail spacecraft of the Solar Polar Imager (SPI) mission. A reference SPI sailcraft, consisting of a $160-\mathrm{m}, 150-\mathrm{kg}$ square solar sail, a $250-\mathrm{kg}$ spacecraft bus, and 50-kg science payloads, has a nominal solar thrust force of $160 \mathrm{mN}$ (at $1 \mathrm{AU}$ ), an uncertain center-of-mass/center-of-pressure offset of $\pm 0.4 \mathrm{~m}$, and a characteristic acceleration of $0.35 \mathrm{~mm} / \mathrm{s}^{2}$. This paper has focused on the solar sailing phase of the SPI mission. The simplicity of a quaternion-based attitude control system approach has been demonstrated for the case of coupled attitude and trajectory control employing the cone and clock angles of the solar thrust vector as trajectory control inputs. A relatively fast, 70-deg pitch reorientation within $3 \mathrm{hrs}$ every half orbit during the orbit cranking phase has been shown to be feasible, with the primary ACS, for possible solar observations even during the 5-yr cranking orbit phase. 

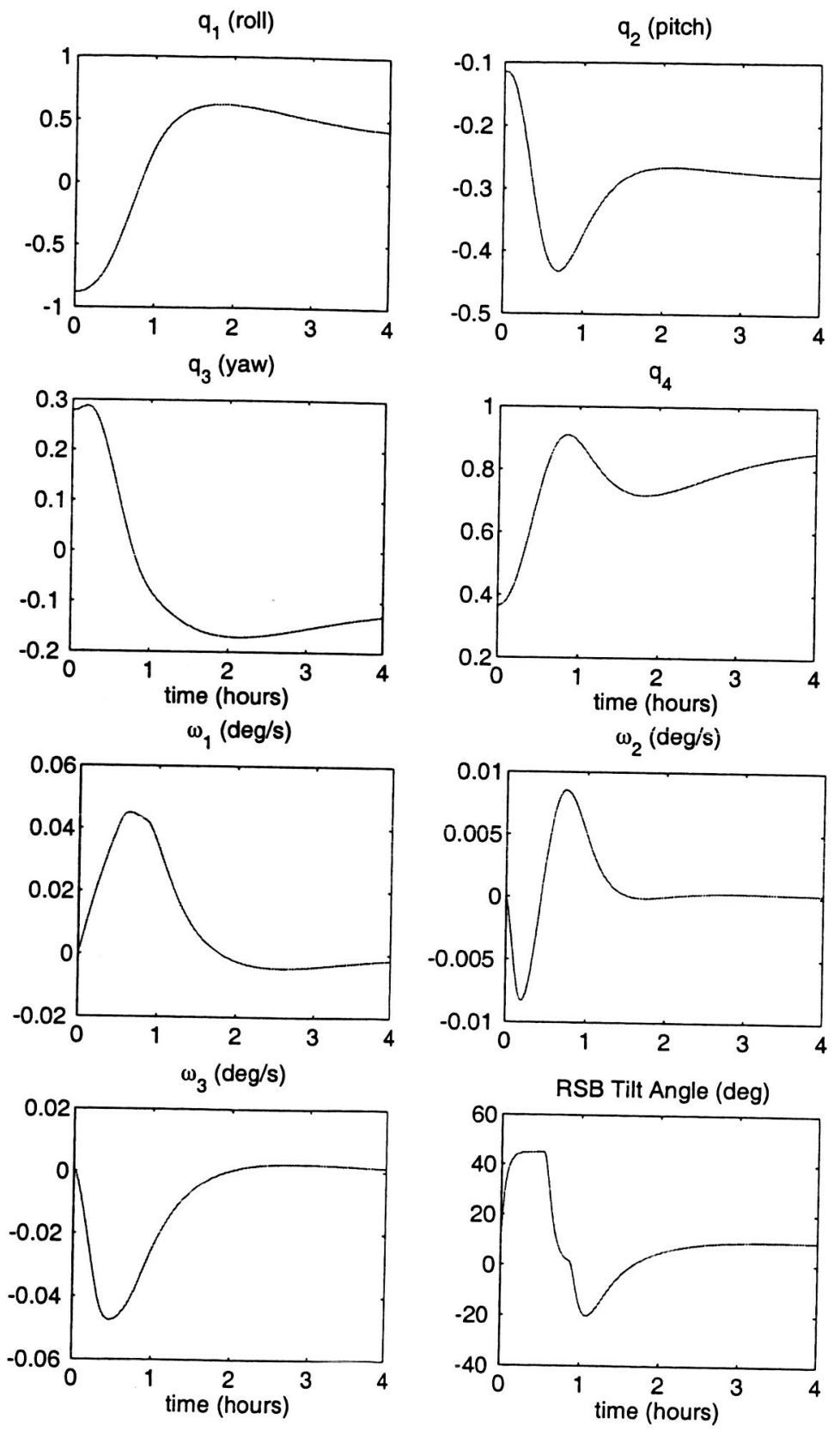

Figure 15. A 180-deg $\delta$ clock-angle maneuver with a fixed 35-deg cone-angle command. 

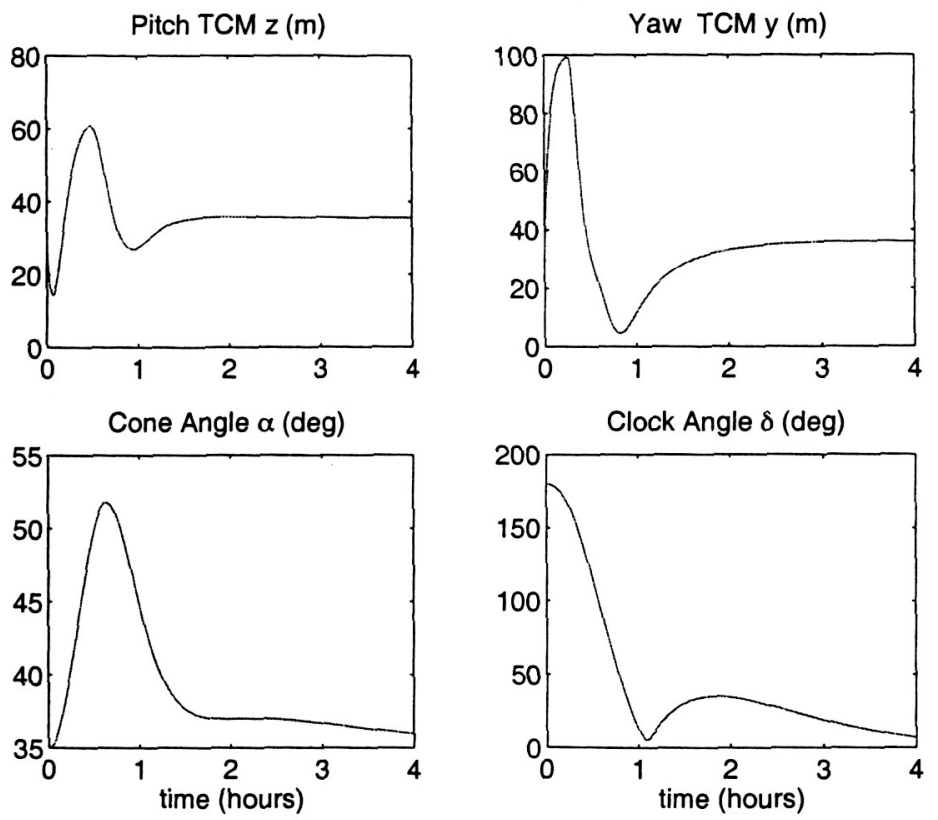

Figure 16. A 180-deg $\delta$ clock-angle maneuver with a fixed 35-deg cone-angle command (continued).

\section{Acknowledgments}

The work described in this paper was funded in whole or in part by the In-Space Propulsion Technology Program, which is managed by NASA's Science Mission Directorate in Washington, D.C., and implemented by the In-Space Propulsion Technology Office at Marshall Space Flight Center in Huntsville, Alabama. The program objective is to develop in-space propulsion technologies that can enable or benefit near and midterm NASA space science missions by significantly reducing cost, mass or travel times. The authors would like to thank E. Montgomery, G. Garbe, J. Presson, A. Heaton, and M. Whorton at NASA Marshall Space Flight Center for their financial and technical support. Special thanks also go to C. Sauer, J. Ayon, and E. Mettler at JPL for their help in formulating the AOCS design problem of a 160-m sailcraft of the SPI Vision mission.

\section{References}

${ }^{1}$ Garbe, G. and Montgomery, E., "An Overview of NASA's Solar Sail Propulsion Project," AIAA-2003-4662, 39th AIAA/ASME/SAE/ASEE Joint Propulsion Conference and Exhibit, Huntsville, AL, July 20-23, 2003.

${ }^{2}$ Montgomery, E. and Johnson, L., "Development of Solar Sail Propulsion for Inner Solar System NASA Science Missions," AIAA-2004-3992, 40th AIAA/ASME/SAE/ASEE Joint Propulsion Conference and Exhibit, Fort Lauderdale, FL, July 11-14, 2004.

${ }^{3}$ Montgomery, E., "Technology Advancement for Solar Sail Propulsion (SSP) for NASA Science Missions to the Inner Solar System," Solar Sail Technologies and Applications Conference, NASA GSFC, Sept. 28-29, 2004. (http://lws.gsfc.nasa.gov/solar_sails_conf/Montgomery.pdf)

${ }^{4}$ Murphy, N., "Solar Polar Imager Vision Mission Overview," Solar Sail Technologies and Applications Conference, NASA GSFC, Sept. 28-29, 2004. (http://lws.gsfc.nasa.gov/solar_sails_conf/NMurphy.pdf)

${ }^{5}$ Murphy, D. and Wie, B., "Robust Thrust Control Authority for a Scalable Sailcraft," AAS-04-285, 14th AAS/AIAA Space Flight Mechanics Conference, Maui, Hawaii, Feb. 8-12, 2004.

${ }^{6}$ Brady, T., Tillier, C., Brown, R., Jimenez, A., and Kourepenis, A., "The Inertial Stellar Compass: A New Direction in Spacecraft Attitude Determination," SSC02-II-1, 16th Annual AIAA/USU Conference on Small Satellites, Logan, Utah, August 2002.

${ }^{7}$ Wie, B., Murphy, D., Thomas, S., and Paluszek, M., "Robust Attitude Control Systems Design for Solar Sail Spacecraft (Part One): Propellantless Primary ACS," AIAA-2004-5010, AIAA Guidance, Navigation, and Control Conference, Providence, RI, August 16-19, 2004. 

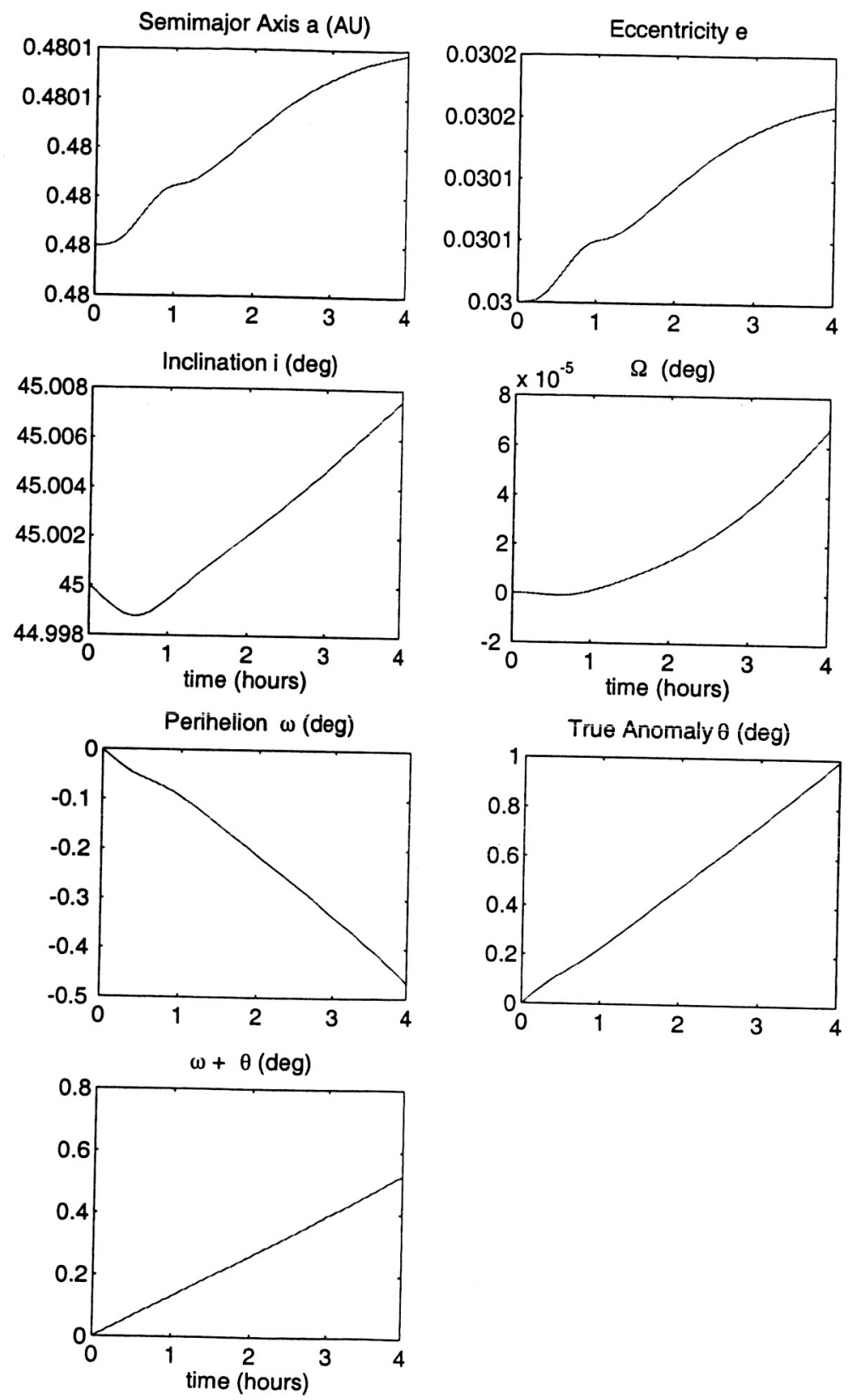

Figure 17. A 180-deg $\delta$ clock-angle maneuver with a fixed 35-deg cone-angle command (continued). 

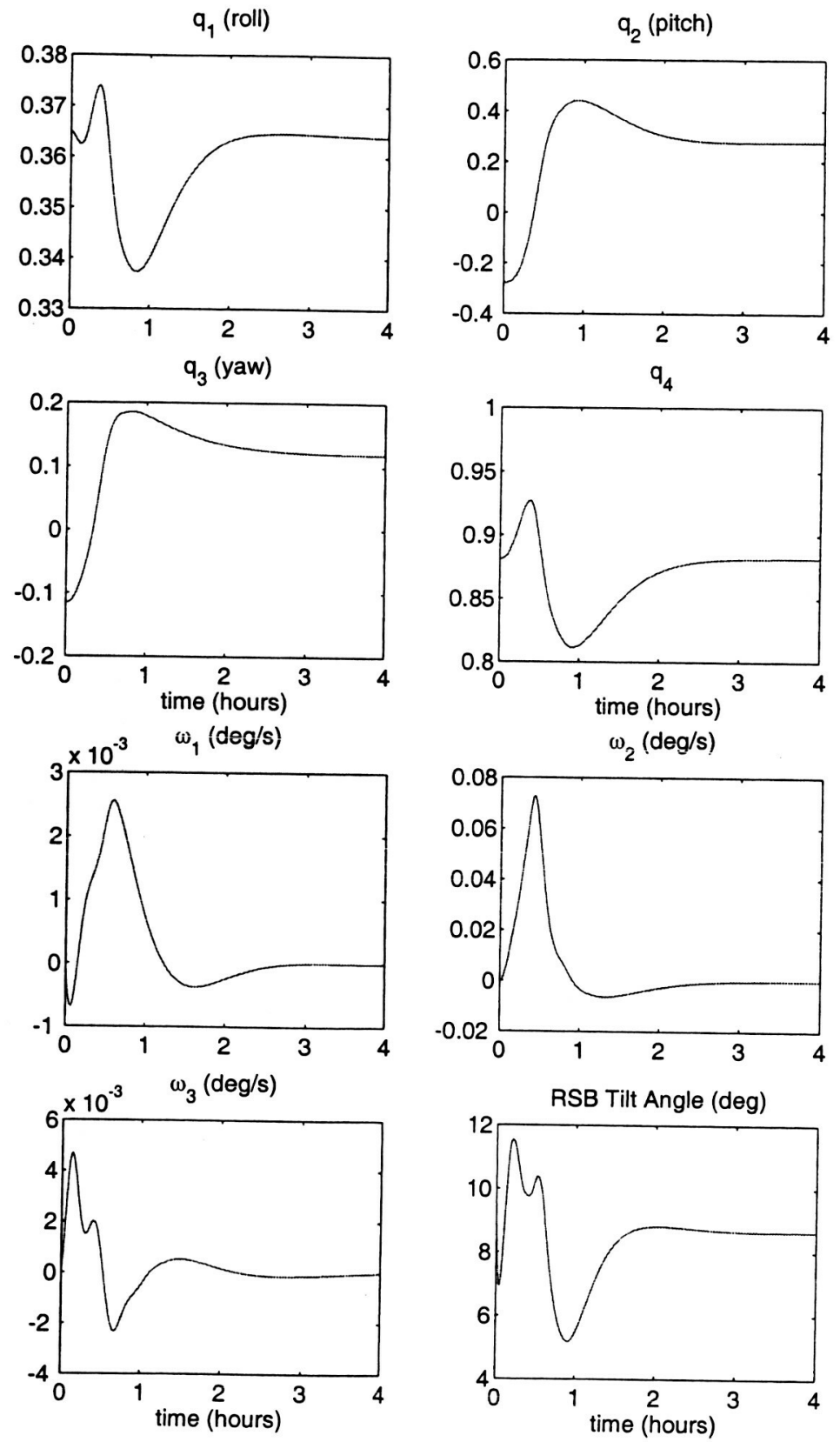

Figure 18. A direct 70-deg pitch-axis maneuver. 

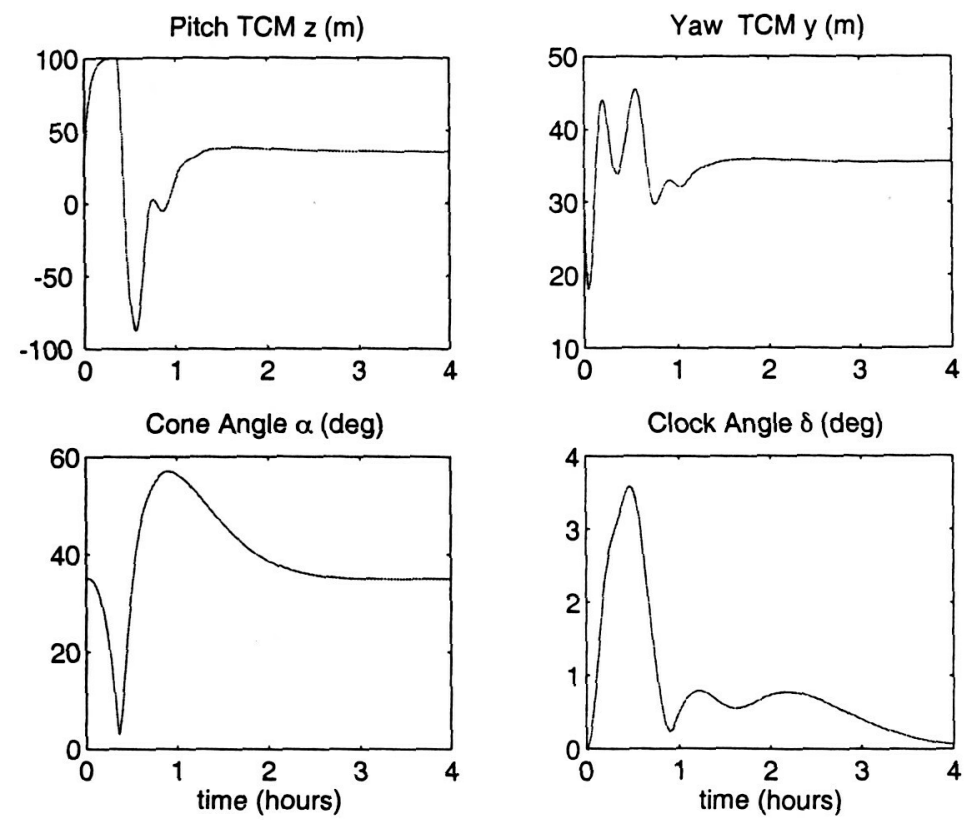

Figure 19. A direct 70-deg pitch-axis maneuver (continued).

${ }^{8}$ Wie, B., Murphy, D., Thomas, S., and Paluszek, M., "Robust Attitude Control Systems Design for Solar Sail Spacecraft (Part Two): microPPT-based Backup ACS," AIAA-2004-5011, AIAA Guidance, Navigation, and Control Conference, Providence, RI, August 16-19, 2004.

${ }^{9}$ Thomas, S., Paluszek, M., Wie, B., and Murphy, D., "Design and Simulation of Sailcraft Attitude Control Systems Using the Solar Sail Control Toolbox," AIAA-2004-4890, AIAA Guidance, Navigation, and Control Conference, Providence, RI, August 16- 19, 2004.

${ }^{10}$ Wie, B., "Solar Sail Attitude Control and Dynamics: Parts 1 and 2," Journal of Guidance, Control, and Dynamics, Vol. 27, No. 4, pp. 526-535, pp. 536-544.

${ }^{11}$ Thomas, S., Paluszek, M., Wie, B., and Murphy, D., "AOCS Performance and Stability Validation for a 160-m Solar Sail with Control-Structure Interactions," AIAA-2005-3926, 41st AIAA/ASME/SAE/ASEE Joint Propulsion Conference and Exhibit, Tucson, AZ, July 10-13, 2005.

${ }^{12}$ Wie, B., "Solar Sailing Kinetic Energy Interceptor (KEI) Mission for Impacting/Deflecting Near-Earth Asteroids," AIAA-2005-3725, 41st AIAA/ASME/SAE/ASEE Joint Propulsion Conference and Exhibit, Tucson, AZ, July 10-13, 2005.

${ }^{13}$ Dachwald, B. and Wie, B., "Solar Sailing Trajectory Design for Optimal Intercept/Impact/Deflection of NearEarth Asteroids," AIAA-2005-6176, AIAA Guidance, Navigation, and Control Conference, San Francisco, CA, August 15-18, 2005.

${ }^{14}$ Wie, B. and Murphy, D., "MicroPPT-Based Secondary/Backup ACS for a 160-m, 450-kg Solar Sail Spacecraft," AIAA-2005-3724, 41st AIA A/ASME/SAE/ASEE Joint Propulsion Conference and Exhibit, Tucson, AZ, July 10-13, 2005.

${ }^{15}$ McInnes, C. R., Solar Sailing: Technology, Dynamics and Mission Applications, Springer Praxis Publishing, 1999, Chapter 4.

${ }^{16}$ Yen, C.-W., "Solar Sail Geostorm Mission," AAS-04-107 14th AAS/AIAA Space Flight Mechanics Conference, Maui, HI, Feb. 8-12, 2004.

${ }^{17}$ Sauer, C. G., "The L1-Diamond Affair," AAS-04-278 14th AAS/AIAA Space Flight Mechanics Conference, Maui, HI, Feb. 8-12, 2004.

${ }^{18}$ Lisano, M. E., "A Practical Six-Degree-of-Freedom Solar Sail Dynamics Model for Optimizing Solar Sail Trajectories with Torque Constraints," AIAA-2004-4891, AIAA Guidance, Navigation, and Control Conference, Providence, RI, August 16-19, 2004.

${ }^{19}$ Wie, B., "A Quaternion-Based ACS for Thrust Vector Control of Solar Sail Spacecraft," AIAA-2005-6086, AIAA Guidance, Navigation, and Control Conference, San Francisco, CA, August 15-18, 2005.

${ }^{20}$ Wie, B. and Barba, P.M., "Quaternion Feedback for Spacecraft Large Angle Maneuvers," Journal of Guidance, Control, and Dynamics, Vol. 8, No. 3, 1985, pp. 360-365.

${ }^{21}$ Wie, B., Space Vehicle Dynamics and Control, AIAA Education Series, AIAA, 1998, Chapters 5-7. 

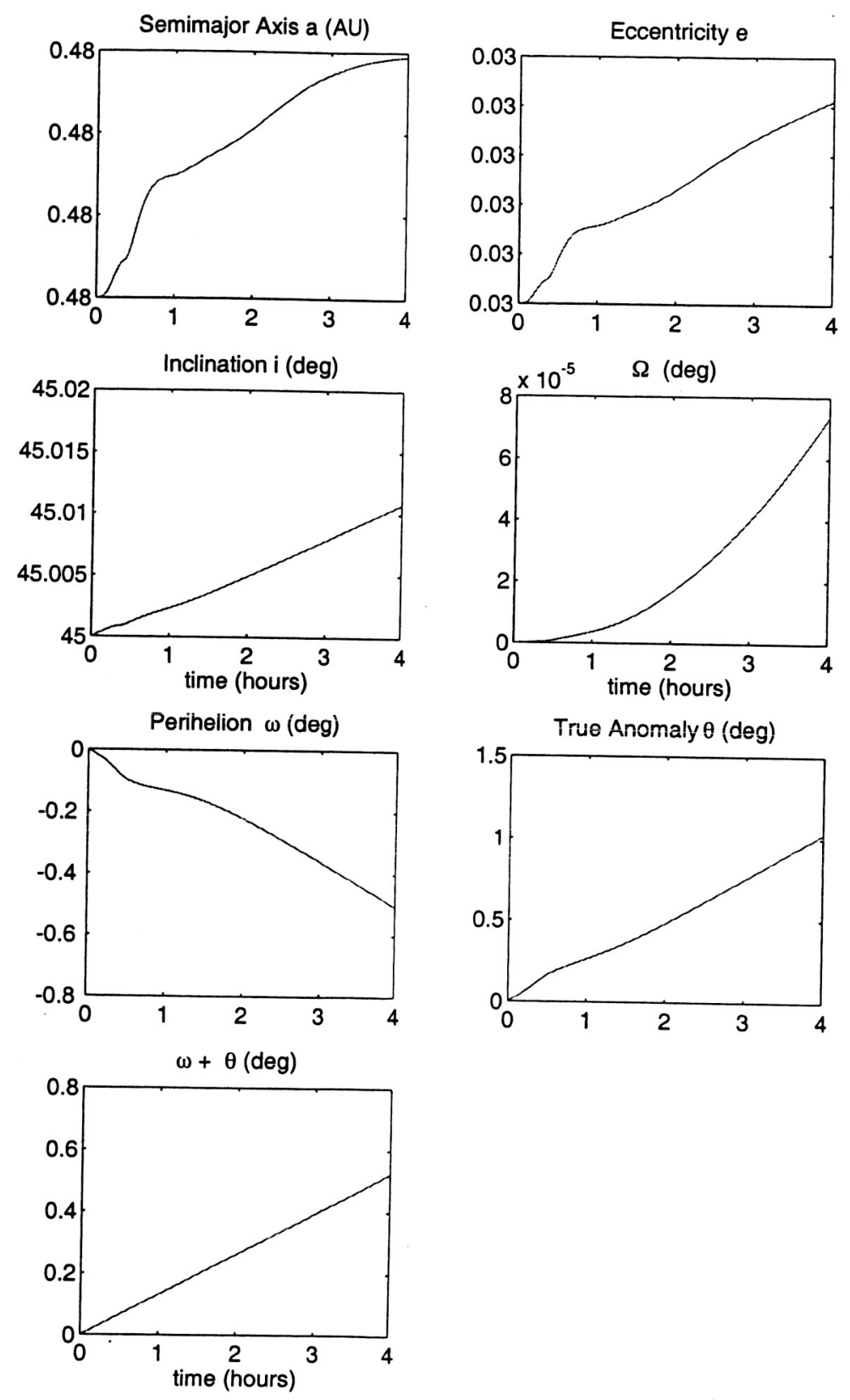

Figure 20. A direct 70-deg pitch-axis maneuver (continued). 

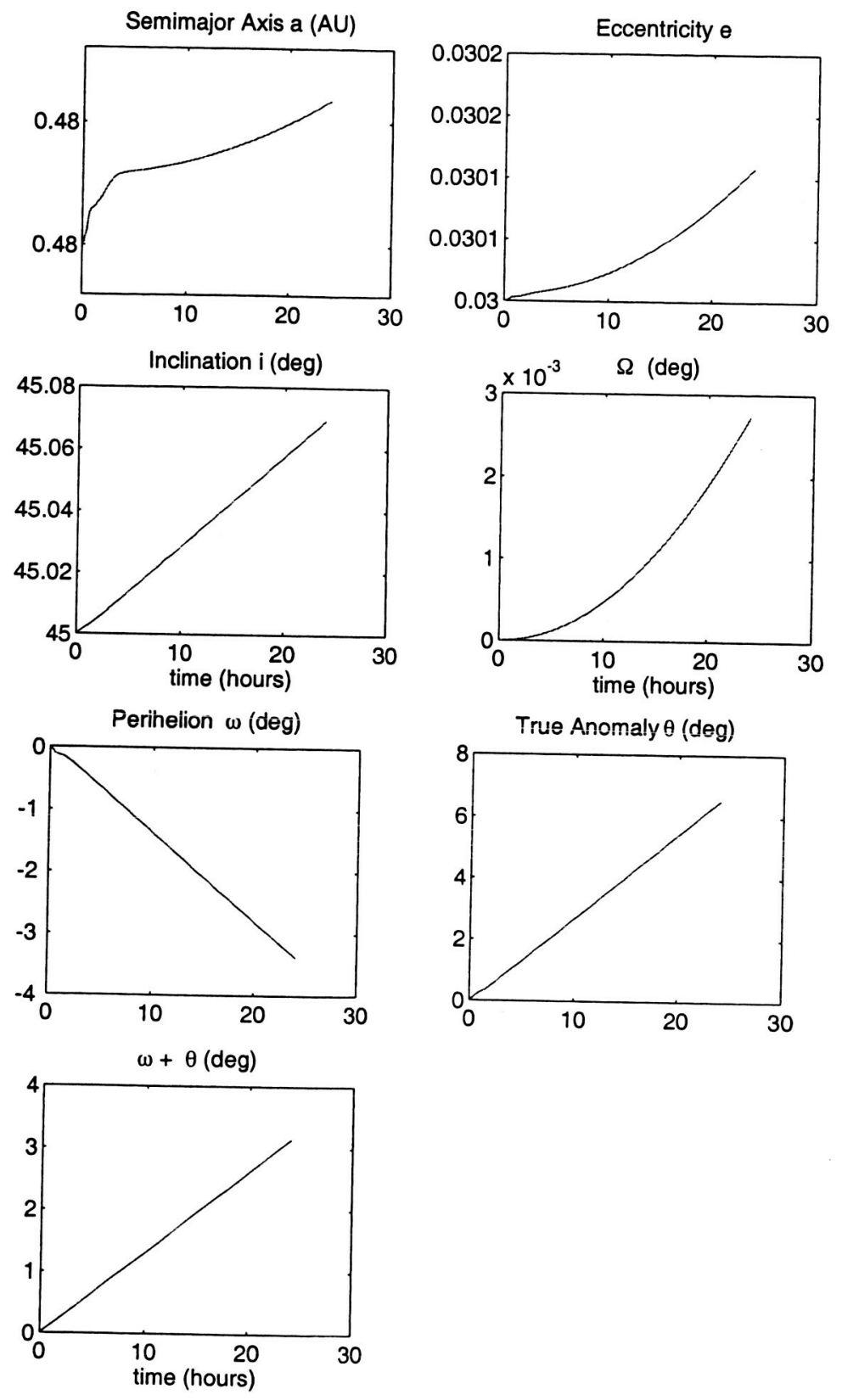

Figure 21. 24-hr simulation result showing a 0.06-deg inclination increase per day. 
${ }^{22}$ Wie, B., Heiberg, C., Bailey, D., "Rapid Multi-Target Acquisition and Pointing Control of Agile Spacecraft," Journal of Guidance, Control, and Dynamics, Vol. 25, No. 1, 2002, pp. 96-104.

${ }^{23}$ Battin, R. H., An Introduction to the Mathematics and Methods of Astrodynamics, AIAA Education Series, AIAA, 1987. 